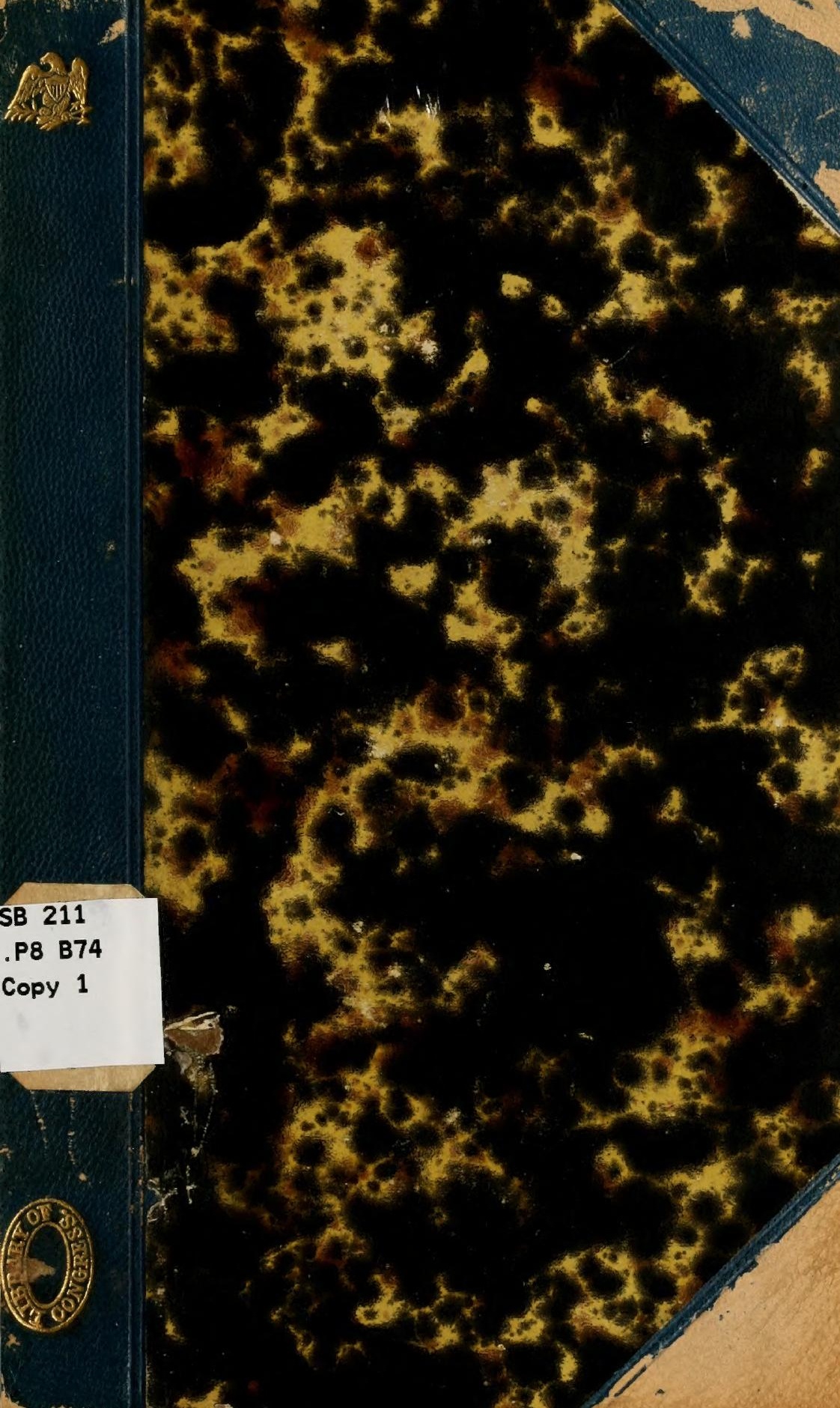




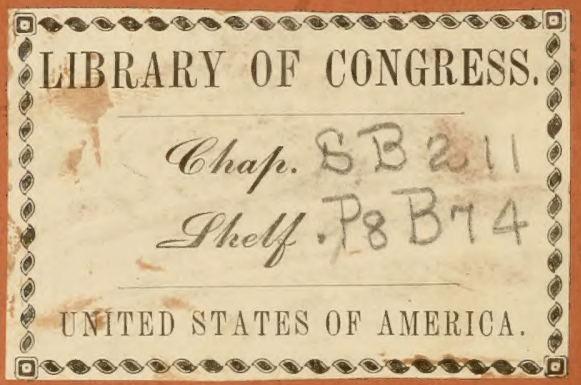




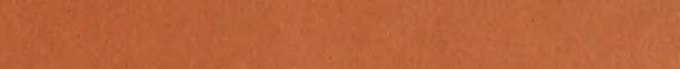

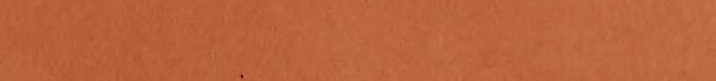

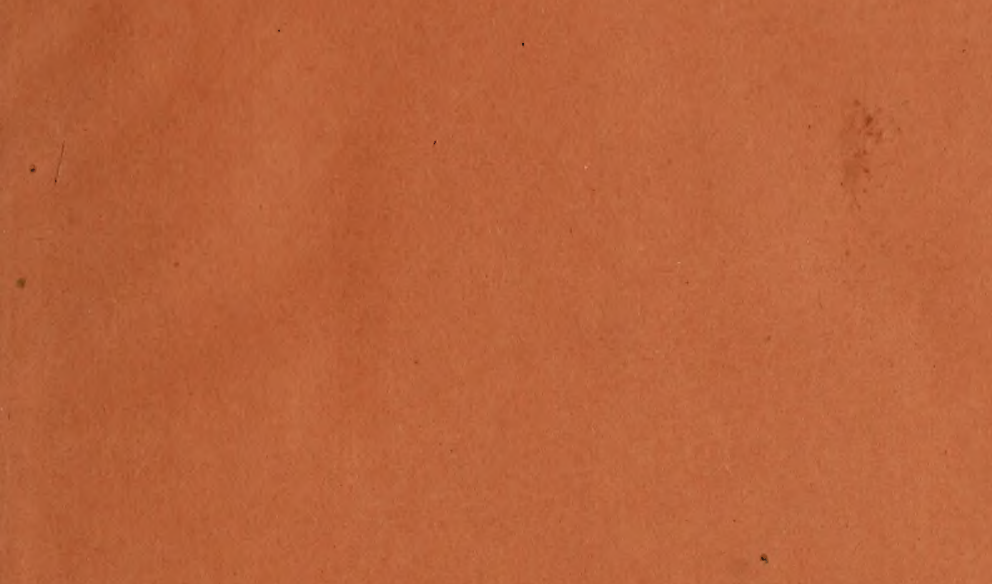

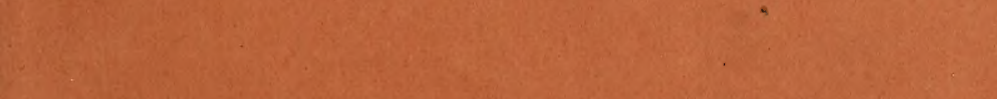

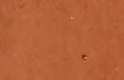







\title{
OBSERVATIONS
}

\section{ON THE POTATOE,}

AND A

\section{REMEDY FOR THE POTATOE PLAGUE.}

\author{
IN TWO PARTS.
}

CONTAINING A

\section{HISTORY OF THE POTATOE,}

\author{
ITS CULTIVATION, AND USES,
}

ALSO

\section{A TREATISE ON THE POTATOE MALADY,}

ITS ORIGIN AND APPEARANCES IN DIFFERENT COUNTRIES, A VIEW OF VARIOUS THEORIES CONCERNING IT, WITH THE REMEDIES PROPOSED,

\section{AND AN INQUIRY}

INTO THE CAUSES PRODUCING THE DISEASE, WITH DIRECTIONS FOR STAYING ITS FURTHER PROGRESS.

\section{BY CHARLES P. BOSSON,}

Member of the Massachusetts Horticultural Society, Editor of the N. E. Agriculturist, Author of a Treatise on the Sugar Beet, etc., ctc.

B O S T ON :

PUBLISHED BY E. L. PRATT. 1846. 


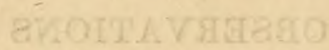

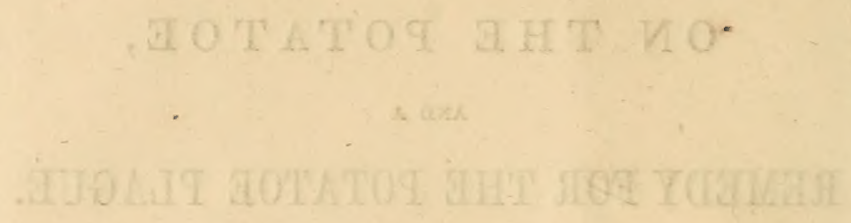

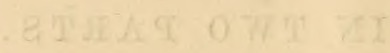

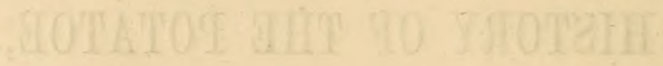

Entered according to Act of Congress, in the year 1846, By E. L. PRATT,

In the Clerk's Office of the District Court of the District of Massachusetts.

Boston :

Rrinted by S. N. Dickinson \& Co.

No. 52 Washington $8 t$.

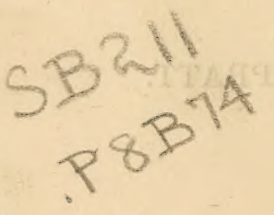






\section{H A P T E R I.}

Some Account of the Appearance of the Disease in different parts of the World.

Action of the British Government - Report of the British Commissioners - Proceedings of the French Academy of Arts and SciencesReport of I'rofessor Morren-H. S. Thompson on the prevention of curl and dry rot in potatoes - experiments with ripe and unripe seed - Causes of the disease stated-Conclusions of Mr. ThompsonObjections to his theory considered, . . : . . . 57-77

\section{H A P T E R I I.}

$\Lambda$ View of the different Theories entertained on the Potatoe Plague.

First symptom of degeneracy of the plant in Scotland - Diseased tubers examined - Seeds from an over-grown crop will always be a diseased crop - Remedy proposed - Raising from the apple - Disease supposed to be cansed by rust - European pamphlets on this subject - Result of chemical investigations - Conversion of diseased potatoes into starch - Evil ascribed to too much moisture - Fungi analogous to smut in barley - Remedies against fungus - Disease ascribed to various causes - Professor Liebig's opinion - Ascribed to fungus in the leaf - Sporules of fungi-Experiments in planting diseased potatoes - Disease supposed to attack the stem primarily On new high ground the crop less affected - Opinion of J. E. Teschemacher - Salt a remedy - Analysis of sea-weed-A. B. Allen's opinion - Cause of fungi, and remedies proposed, . . . 76-94

\section{H A P T ER III.}

\section{Cause of the Disease and Remedies stated.}

Review of the prevailing theories - The discase exists in the potatoe - If fungi is the cause a certain remedy is at hand-Causes of the disease-Over Ripening-Over Cultivation-DeterioraTION of SEed-CARELESSNess in Selecting SEed-Improper management in taking up potatoes - An improved method of planting - Table - Selecting potatoes for seed, . . . . 95-116 



\section{O NTENTS.}

\section{P A R T I.}

\section{H A P T E R I.}

Some account of the early history of the potatoe-Its introduction into Great Britain and other European countries - Extravagant price of potatoes,

\section{H A P T E I I.}

\section{On the Cultivation of the Potatoe.}

When first cultivated as a field crop - Thaer's principles of agriculture-Classification of varieties - Skin of the potatoe-Color of the flesh-Nutritive matter contained in different sorts-Soils - Clearings and marsh lands - Strong land - Setting potatoes Best sort for seed - Comparative value of whole and cut tubers Quantity of produce is in proportion to seed - Plowing the land Manner of setting potatoes - Influence of the weather in planting, 7-15

\section{CHAPTER III.}

\section{On Planting Potatoes, Harvesting, \&c.}

The marking plow - Harrowing - First cultivation - Tenacious and wet soils - Effect of cutting off the blossoms - Effect of cutting off the leaves - Digging the crops - Gathering - Potatoes dug in dry 


\section{CONTENTS.}

weatler - In damp weather - Heaps of potatoes - Management of the heaps in autumn. . . . . . . . 16-20

\section{H A P TER IV.}

An Account of Diseases which have previously affected the Crop, and the Remedies that have been found efficacious.

Subject to disease at an early period - The curl - Probable causes of the curl - Observations of Mr. Kinight - Discovery by Mr. CrozerFailure or taint - The drought of 1526 - Remarks of Mr. ShirreffDeterioration of varieties - The potatoe a short lived plant - Late planting recommended by Mr. Knight-Over ripened and under ripened seed - Efiects of comparative wet and dry soils on whole and cut tubers - Scab or ulcerated surface - Causes of total or partial failure have existed from a very early date-Planting of entire tubers recommended - Rust, black rust - A description of this disease - Cause assigned - Observations on the disense from various authorities - Dr. Van MIartius on the epidemic diseases of potatoes Views of Rev. Mr. Allen, . . . . . . . . 21-31

\section{CII $\triangle$ P'TER V.}

\section{Various Uses to which Potatoes are applied.}

Comparative value of potatoes and grain - P'otatoe flour - Farina in potatoes - Meal of potatoes may bo preserved-Tapioca from potatoes The process described-Potash from potatoe leaves and stalks; Potatoes for cleaning woollens - Making wine and ardent spirits - German method of making potatoe flum - Method of using potatoes in Denmark and Norway,

\section{P A R T I I.}

\section{THE POTATOE PLAGUE.}

\section{Preliminary Remarks.}

Importance of the subject - Extent of the crop in the United States -

Review of various theories concerning the malady, 


\section{P R E A C E.}

Poxatoes, as an article of human food, are, next to wheat, of the greatest importance in the eye of the political economist. From no other crop that can be cultivated, will the public derive so much food as from this valuable esculent; and it admits of demonstration, that an acre of potatoes will feed double the number of people that can be fed from an acre of wheat; they are relished by every palate, and, it is believed, there is hardly a dinner served up in any country where they are cultivated, without them.

An article of such vast importance, - that forms a grand staple of our agriculture, - the principal source of national wealth, - that forms a prominent article in the diet of every individual, - deserves the particular attention of every one; and the object of this treatise is, to collate the most important facts in the history of this esculent, as well as the opinions and practice of the best cultivators, with regard to its management, the cure of diseases affecting it, and every other item of information respecting it that can be turned to profitable account by our own farmers.

But more particularly, and above all, my object has been 
to collect facts, opinions and remedies, on the alarming and fatal disease that now threatens destruction to this UNIVERSAL FOOD FOR MAN, and to furnish the conclusion which eminent practical men have arrired at, both in this country and Europe, on the causes of the disease, and the appropriate remedy for it. It is believed that a sure remedy has been discovered, and the subsequent pages of this book will detail such facts as will encourage furmers to proceed with the cultivation of the potatoe crop in all confidence.

Independent of the particular olject for which this small treatise is especially designed, to wit: - the cure of the Potatoe Plague, farmers will find much valuable information on the general cultivation of this crop, which will be valuable for reference long after the plague, (may its reign be short!) has disappeared. 


\section{IIISTORY, CULTURE, AND DISELSES OF TIIE POTATOE.}

\section{P A R T I.}

\section{CHAPTER I.}

Some Account of the Early Ifistory of the Potatoe; its Introduction into Great Britain and other European Countries.

Trie Potatoe now in use, (Solanum tuberosum, was brought to England by the Colonists sent out lyy Sir Walter Raleigh, under the authority of his patent, granted by Queen Elizabeth, "for discovering and planting new countries, not possessed hy Christians," which passed the great seal in 158. Some of Sir Wralter's ships sailed in the same year; others, on board one of which was Thomas IIerriot, afterwards known as a mathematician, in $\mathbf{1 5 8 5}$; the whole, however, returned, and probably brought with them the Potatoe, on the 27 th of July, 1586.

This Mr. Thomas IIerriot, who was probably sent out to examine the country, and report to his employers the nature and produce of the soil, wrote an account of it, which is printed in De Bry's Collection of Voyages, vol. I. In this account, under the article of roots, page 17 , he describes a 
plant called Openawh: "These roots," says he, "are round, some as large as a walnut, others much larger; they grow in damp soil, many hanging together, as if fixed on ropes; they are good food, either boiled or roasted."

Gerarl, in his IIerbal, published 1597, gives a figure of the potatoe, under the name of Potatoe of Virginia, otherwise called Norembaga.

The manuscript minutes of the Royal Society, December 13, 1693, tell us, that Sir Robert Sonthwell, then President, informed the fellows, at a meeting, that his grandfatlier brought potatoes into Ireland, who first had them from Sir Walter Raleigh.

This evidence proves, not unsatisfactorily, that the potatoe was first brought into England, either in the year 1586, or very soon after, and sent from thence to Ireland, without delay, by Sir Robert Southwell's ancestor, where it was cherished and cultivated for food before the good people of England knew its value; for Gerard, who had this plant in his garden, in 1597, recommends the root to be eaten as a delicate dish, - not as common food.

It appears, however, that it first came into Europe at an earlier period, and by a different channel; for Clusius, who at that time resided at. Viemn, first received the potatoe in 1598, who had procured it the year before from one of the attendants of the Pope's legate, unler the name of Taratoufli ; and learned from him, that in Italy, where it was then in use, no one certainly knew whether it originally came from Spain or from America.

Peter Cieca, in his Chronicle, printed in 1553, tells us, chap. xi., p. 49, that the inhalitants of Quito and its vicinity, have, besides Maize, a tuberous root, which they eat, and call papus; this, Clusius guesses to be the plant he received from Flanders, and this conjecture has been confirmed by the 
accounts of travellers, who have since that period visited the country.

From these details we may fairly infer, that potatoes were first brought into Europe from the mountainous parts of South America, in the neighborhood of Quito; and, as the Spaniards were the sole possessors of that country, there is little doubt of their having been first carried into Spain; but as it would take some time to introduce them into use in that country, and afterwards to make the Italians so well acquainted with them as to give them a name,* there is every reason to believe they had been several years in Europe, before they were sent to Clusius.

The name of the root in South America, is Papas, and in Virginia, it was Openarwh ; the name of potatoe was evidently applied to it on account of its similarity in appearance to the Battata, or Sweet Potatoe; and our potatoe appears to have been distinguished from that root, by the apellative of Potatoe of Virginia, till the year 1640, if not longer. $\dagger$

Several authors have asserted, that potatoes were first discovered by Sir Francis Drakie, in the South Seas; and others, that they were introduced into England by Sir John Hawkins; but in both instances the plant alluded to is clearly the sweet potatoe, which was used in England as a delicacy, long before the introduction of our potatoes; it was imported in considerable quantities from Spain, and the Canaries, and was supposed to possess the power of restoring decryed vigor. The kissing comforts of Falstaff, + and other confections of similar imaginary qualities, with which our ancestors were duped, were principally made of these eringo roots.

* Taratoufli signifies also truffles.

† Gerard's Herbal, by Johnson, p. 729.

f "Let it rain potatoes, and hail kissing comforts." - Merry Wives of Windsor, Act V., Scene V. 
The potatoes themselves were sold by itinerant dealers, chiefly in the neighborhood of the Royal Exchange, and purchased when scarce, at no inconsiderable cost, by those who had faith in their alleged properties. The allusions to this opinion are very frequent in the plays of that age. 


\section{CHAPTER II.}

\section{Cultivation of the Potatoe.}

IT was not till 1771 and 1772 , that the practice of cultivating potatoes as a field crop began to acquire supporters; but at that time all the grain crops failed, and the famine which ensued led to the discovery that proper and sufficient nourishment might be derived from those rery potatoes which had hitherto only been regarded as a luxury, just as well as from bread. Still its cultivation did not exceed the wants of man himself. It was not till a later period that the practice of giving the refuse and surplus to the cattle began to creep in. But it was thus gradually discovered that potatoes might be advantageously cultirated as food for live stock. Bergen, in his "Introduction to the Management of Live Stock," was the first to recommend the practice of this cultivation on a large scale, and the use of a kind of horn hoe to save manual labor. At the present day it appears scarcely credible that the extreme utility of this plant should have so long remained unknown, and that so much difference of opinion should have existed on the propriety of raising it on extensive tracts of land.

"There is no plant," says Thaer, in his "Principles of Agriculture," "to which I have paid greater attention than to the potatoe. Eron before I entered upon the practice of agriculture, my attention was excited by the innumerable varieties which were produced by raising it from seed. I 
treated it in various ways at that time, merely with a view to vegetable physiology, my ohject being to discover whether the distinguishing characters of these varieties were due to the nature of the soil, or the morle of fertilizing it. Since that time I have, in raising the potatoe, tricd all the methods proposed by others, as well as those which I have myself derised. As far as the quantity of produce is concerned, the results of various modes of planting and cultivation have shown but little difference, unless, indecd, the cultiration were altogether neglected or badly arranged. 'The quantity of produce was found to depend upon the soil, when the species cultirated was the same. But the manual labor, and, consequently, the net profit, raried considerably. I have done my utmost to reduce this manual labor to the smallest possible amount, without sensibly diminishing the produce, for, in the raising of potatoes the rent of land is much less considerable than the expenses of cultivation.

"I will renture to say, that I have attained this object more nearly than any one else, and that I have found myself nearer and nearer to it at the end of almost erery successive year. I therefore beg those persons who have read my former works, " and the observations which I have made on the culture of the potatoe, to consider such observations as the result of my apprenticeship, and those which I am now about to make, as more complete and matured."

In order to make some sort of classification of the innumerable varieties of the potatoe, we must confine our attention to the most useful part, - the tuber. It is true that the leares and the flowers appear to bear some relation to the form of the tuber, but the particular examination of them belongs more properly to the botanical cultivator.

The skin of the potatoe is, in some varieties, of a dark color, approaching almost to blackness; in others of a red-

* Thaer's English Agriculture, vols. 1 and 2. 
dish violet, which varies to pale, brownish, or yellowish red; in others, again, of a whitish yellow.

The color of the flesh is sometimes yellow, sometimes whitish, or perfectly white, and sometimes slightly tinged -with red.

The several varieties of the potatoe hare different times of arriving at maturity; that is to say, at the state in which the tulhers are detaclied from the maternal plant, and the latter dies.

But the points of difference we have chicfly to consider, relate to the consistence of the potatoe and the quantity of stareh contained in it. Some varieties are very spongy, their interstices are filled with water, their specific gravity is small, and they contain but a small quantity of nutriment in a given bulk.

'The flaror of some potatoes is very agrecable; of others, rery disagrecable. Some improve by keeping, others are best when fresh gathered.

Some cook speedily and burst, others resist the action of stenm and hot water for a long time.

Some rarieties require a dry soil, becoming quite watery and hollow in the midtle when grown on land which requires much moisture; they also secrete water in their cavities. Others, on the contrary, are very small, and are scarcely worth the expense of eultivation when grown on a dry soil.

Some put out long filaments into the soil; others press their tubers so closely together, that they show themselves above ground.

Some varieties thrive particularly well on marshy land, others perish on it, and thrive on an argillaceous soil.

All these particulars must be taken into account, when a selection is to be made of varietics for cultivation. The culture of a new variety should never be undertaken on a large scale, till a proper trial has been made of it. 
The amount of produce of each rariety must be taken into consideration, but the value calculated according to the quantity of nutritive matter contained in it. This may be jutged of approximately by the sensation which the fleshy part of the tuber produces when applied to the tougue; or more accurately hy cutting the tubers in pieces, drying them, and comparing their weight in the dry state with what it was before; but an accurate estimate is only to be made by chemical analysis. Great buk is by no means desirable, if it be not attended with increase in the quantity of starch: for the potatoes then take up, more room, although their intrinsic value remains the same, and they are more likely to be spoiled. In other respects when potatoes are cultivated for sale, the choice must be directerl by the taste of purchasers.

Potatoes will grow on soils of all descriptions, and in favorable weather will yield a goor elop, even on moving sand, provided that it has been well manured. On a stony soil, well prepared, and lightened with dung, containing straw, the success of the potatoe is certain; though a sandy soil is best adapted to it.

On clearings and marsh lands, provided the soil has been well drained, and especially if the turf has been burned upon it, potatoes thrive particularly well, and sometimes yield a very large produce.

It is generally admitted that potatoes grow larger after recent manuring; they will, however, yield a good crop even when raised as a second or third crop; but the soil will then be greatly exhausted. I have never even thought of asserting that potatoes do not imporerish the soil; on the contrary I have stated that they do so ; they do not, however, exhaust the resources of the establishment in general, but increase those resources to a considerable extent, if they are giecn as food to the cattle.

On strong land, fresh dung mixed with straw is most ben- 
eficial to potatoes, and the more so in proportion to the closeness of its contact with them; it should, therefore, not be carted and put into the ground till just before the seed time of ploughing. But for light soils, the dung must either be in a more adranced stage of decomposition, or it must be mixed with the earth by several ploughings.

Very healthy potatoes are also produced by the use of other actire manures, such as scrapings of horn spread in the furrows at the seed time ploughing, rags of wool, and the refuse of the tan yard. Turning sheep on to the field after the potatoes have been set, is likewise very efficacious in promoting their growtl, but it gives the tubers a bat flavor. There is also a limit to the degree of cultivation proper for potatoes; if it be surpassed the haulm becomes excessively large, and falls upon the ground; the number of tubers is then much diminished.

In setting potatoes, it is necessary to select the most healthy and vigorous tubers; not such as have already been deprived of two or three of their buds, because the most vigorous buds are always the first chosen. Especially must those be rejected which have been much exposed to the cold, even though they should not have been much injured by frost. Potatoes grown in pits, mounds, or hollows, where frost has penetrated and destroyed a portion of tubers, are very uncertain in plantations; I am sure of this from my own experience. They either do not shoot up at all, or produce but feeble plants; great care should therefore be taken to preserve those which are intended for setting.

I am aware that many cultivators have obtained abundant crops of large potatoes by planting none but small tubers; nevertheless I prefer setting those of large and average size, especially for certain varieties. Small tubers have not the same power of germination as large ones, and often do not germinate at all; whereas, those of large size may without injury be cut in halves. 
When circumstances are otherwise farorable, very strong plants are often obtained by setting mere cuttings of potatoes containing a single eye; or, even the eye by itself. But on heary land, which has not been well pulverized, as well as on a sandy soil, there is great danger of failur, if, after setting, or during germination, the weather should be unfavorable for the formation of the plant. To ensure success, this plant must, by means of its feeble roots, immediately seek for nourishment in the soil. It must not encounter a hard picee of ground: for, as it derives no nourishment from the maternal plant, it would then dry up and perish. I therefore abandon this method altogether, although I formerly recommended it; it succeeds very well in gardens, but is very uncertain for potatoe crops grown in the open field.

There will always be a difference of opinion touching the expediency of setting potatoes close together, or far apart; for the decision of this matter depends upon adventitious circumstances; but repeated trials accurately described, seem to show that the quantity of produce is, to a considerable extent, in proportion to that of the sets. The practical results of these trials are as follows:-

1. The amount of net produce, deduction being made for the quantity of potatoes used for setting, bears a tolerably exact proportion to the latter quantity, - that is to say, that one who sets a larger quantity of tubers, will usually obtain a more abundant crop than one who sets a smaller quantity.

2. Fine large tubers produce not only larger potatoes, but also a greater number of them.

3. The degeneracy often observed in potatoes, apparently results from the use of unlealthy plants for setting.

4. Small tubers, and those which are destitute of buds, cannot by any means be recommended for setting.

5. When potatoes of medium quality are planted, it is better to set them whole; but when the tubers are very large, 
the lalses will be found suffieient, provided, however, that they are set rather closely in the rows.

6. It is not adrisilile to cut a potatoe into more than two pieces.

7. It is better to set the tuluers, one by one, and close together, than to put a number of them into the ground together, particularly when all the labor is performed with the plongh, and no cultivation is giren with the hand-hoe.

S. It is not adrisable to plant mere buds ; they often fail.* I give these principles as being in accordance with my own experiments mate on the large scale, with the exception, lowever, of the first. It does appear, from actual experiment, that the quantity of produce is in proportion to that of the potatoes put into the ground. The author deduces a result by diviling his plantation into two parts. In one of these he places the trial in which the quantity set amounted to more than 1,254; and in the other, those in which this quantity was less. In the former the net produce of each row was 16.81 ; in the latter, only 15.41 . These two results are in the proportion of 1000 to 917. The loss in the latter is, therefure, $8 \frac{1}{2}$ per cent., but the difference in the relative quantity of the sets is much greater. Then, again, among the trials included in the latter division, there are several which ought not to be included in the comparison: where, for example, the set consisted of mere eyes, or handfuls of rery small scattered shoots, all of which gave but a very insignificant product. If we take into account those trials only in which good potatoes, or cuttings of them, were set at intervals of $1,2,3$ and 4 decimetres, $\dagger$ it will be found that the difference is very small, not exceeding two and a half per cent.

* German Agricultural Gazette.

t A French measure of about three and a half inches. 
I am willing to admit the existence of this difference, and even of one of five per cent., if the potatoes are set in one part of the rows, at right inches, and in another at twentyfour inches distance; so that the quantity of sets used for the former shall be three times as great as that used for the latter. The quantity obtained from the half in which the potatoes are at the greatest distance apart, will not amount to more than ninety-five bushels bryond that of the scts, while the produce of the other half will amount to one hundred bushels.

On the other liand the practice of setting at greater distances is attended with the following adrantages, in ficld cultivation.

1. Potatoes, especially those fit for setting, bring a much higher price in spring than in autumm, which is the time for gathering; the keeping of them occasions both trouble and risk, and there is always a portion spoiled.

2. Setting at greater distances oceasions saring of manual labor.

3. When the plantations are laid out in rows in all directions, and the distances between the rows are wide enough to allow the plough to pass crosswise, almost all the manual labor which would otherwise be rerquired to weed the spaces will be saved.

4. These ploughings are much more efficacious in cleansing, pulverizing and aerating the land, than they would he if performed in one direction only, so that the object of following one of the principal ents of the culture of weeded crops, is completely attained. We say nothing alout the effect produeel on the potatoes themselres, by cultivation on all sides, since we have admitted, for argument's sake, that those which are cultivated on one side only, yield the greatest increase.

5. The gathering of potatoes is performed with fur greater facility and despateh when they are grown on separate hil- 
locks, tham when they are arranged in continuous lines. My farmere are more willing to raise potatoes planted singly, for the fourteenth part of the produce, than for the tenth when they are planted in rows, for a man will raise eighteen scheffles of the former in a day, where of the latter he would raise only ten, even though they may have been cultivated with the same care. This saving of time in taking the erop is of great importance.

Such are the reasons which induce me to prefer the methol of setting potatoes at moderate distances, and arranging them in lines in all directions. I admit that when this method is arlopted, a somewhat larger extent of surface is required for the proluction of a given quantity; but the great saving of labor, and the expellent preparation of the land which it affords, are of much greater importance.

In setting potatoes regard must be had to the state of the weather. In this conntry I never plant them till the soil has become heited; and I have always observed that the potatoes set last were the first to come up. I have plinted them with suceess till the beginning of June; but I endeavor to get the setting finished by the middle of May. If the soil contain ever so small a quantity of clay, it is absolutely necessary to defer the plauting till it is perfectly dry, and no longer adheres to the implements.

As early as posibible in autumn I break up the soil to the depth of two inches lower than before, and then pass the harrow over it. In winter the dung is carted and uniformly spread. At the beginning of spring, this dung is buried by a liglit plongling. I like to liave a portion of the manure bronght up to the surface by this operation, because a greater quantity is then collected aromel the roots of the potatee. 


\section{CHA P'I'E R II.}

On Planting Potatoes. Ilumesting. Preserring the (rop.

In the preceding chapter I could not resist the tempitation to copy entire Mr. 'Thurer's article on potatoes; it seremerl to me so characterized by dearness and perspicuity, so eminently practical, that I could not, with propriety, withhold it from a compilation of the kind in land; besides the article is new to American reaters, and cannot be uninteresting. I continue in the present chipter, the accomit of Mr. Thaer, embracing some sugerestions, the most important to us at the present time, on the subject of keeping and preserving potatoes through the winter. The extract commences with Mr. Thaer's methorl of planting, which was alluded to in the previous chapter.

By means of the morking plough, or furrower, already noticed, lines, or small furrows, are traced at right angles, or obliquely, to the direction which the plongh is to take. Five persons are then stationcl at equal distances on the line of the plongh, each having assigned to him the space which he is to plant. One plough traces the furrow, which is immediately set with potatoes; two other ploughs then follow, and the potatoes are set in the furrow traced by the third. It will be understood that the persons who set them will have to go from one side to the other, each one keeping within his allotted space. Each potatoe is set at the point of intersec- 
tion of the line traced by the marker, with the furrow formed by the plough. It is of importance that the potatoes be set as close as possillle to the perpendicular side of the furrow, and not on that where the slice has been turned over; for, in the former position, the potato is more likely to remain in its place, and not to be disturbed by the horse's foot.

The best ploughmen must be employed to trace the furrow in which the potatoes are set; first, to ensure that the furrow may be of a proper and uniform depth, - three inches on a heary, and four or fire on a sandy soil. If the laborers are well practised three ploughs and five planters will finish eight acres per day.

A week after the setting, the ground is harrowed, an operation by which a few weeds are destroyed. Great numbers of them afterwarls spring up. Nothing more, however, is done to get rid of them till the potatoes are about to spring up and some of them just beginning to show their leares above grotind. The extirpator is then passed lightly over the whole surface of the field. This may be done without fear of hurting the potatoes. The whole of the weeds are thus destroyed. The soil is left in this state till all the potatoes have come np, and is then harrowed to level it. After this harrowing, the potatoes are as clean as if they had been carefully weeded, so that it only remains to pass the horse-hoe or cultivator over them.

The first cultivation is performer with the small hoe, and should be given in the direction followed by the marking plough or furrower; the second must be performed by the horn-hoe and in the direction of the plough. This will be sufficient in the greater number of cases. If a few weeds should have escaped here and there, by growing close to the potatoes, it will cost but little labor to pull them up while yet in flower.

By these operations the cultivation is completely finished 
before harvest time; and nothing remains to be done for them till they are ready for taking up.

When the soil is tenacious and exposed to humidity, I prefer the following method of cultivation:

The soil having been well prepared, lines crossing transversely are traced with the making plough, and a potatoe set at each intersection. The planting goes on much more quickly in this way; one man can casily plant three acres per day. The small horse-hoe is then passed close to each row, and covers it with earth. When weeds spring up, they are destroyed by passing the large horse-hoe in the same direction, an operation which is performed whether the potatoes have come ul, or not. When the potatoes have grown up to a certain height, the banks or edges formed by the hoe in the last cultivation are cut transversely with the large hoe; another and final cultivation is perhaps given in the direction of the first.

'The advantages presented by this method when applied to an argillaceons soil are very striking. The potatoe is surrounded on all sides lyy light earth, and dımg heaped around it. It is preserved from any exeess of moisture that might injure the crop, because it is placed above the bottom of the furrow by which the water drains off. The soil in which it rests is also thoronghly warmed by the sum. But this method is recommended for those soils only in which potatoes might suffer from excess of moisture, as a sharpisin frost attacking the potatoes before they were gathered might penetrate too deeply into the ridges.

When the earth has been laid up for the last time, and the potatoes begin to blossom, they must be left quiet; for it is then that the young tubers are formed.

Some persons have recommended that the flowers be cut off, in order to increase the growth of the tubers; but the recommendation is absurd. Cullen, of Edinburgh, observed 
some time ago, that the derelopement of the tubers kecps pace with that of the flowers; and experiments especially directed to this point have uniformly shoun thest the erop is much injured by the removal of the flowers.

Cullen also tried the eflect of cutting off the leaves as fast as they grew; the consequence was that the potatoes producel no tubers, but merely filanentous roots. The experiments of Anderson, showing the injury occasioned to potatoes by the hasty removal of their leaves, are conclusive argainst this practice.

The digring the crop has always been looked upon by great cultirators as the most ditlicult part of this branch of hushandry, and has been the main cause of their unwillingness to undertake it on a large scale. This fear, has, howcrer, greatly diminished; it has, indeed, been found, that the getting in may be perforned with greater expedition and facility than was formerly thought possible. They are taken up by means of a mattock, or potatoe loe. When they are planter according to my method, one man ean with such an instrument easily prepare work for twelve pickers. In this manner potatoes can be taken up with less work than with the plough.

In mathering potatoes, I make use of boxes, which hold about thirty bushels, and are placed on waggons. In one side of these boxes is an opening, which shuts by means of a sliding door. When the boxes arrive at the barn the door is opened and a kind of gutter adapted to the opening, and along this gutter the potatoes descend to the place intended for them.

Potatoes dug in dry weather may with safety be placed immediately in a cellar, or store-house, protected from frost; but the place in which they are kept must be left open, to afford a free circulation of air, till cold weather comes on. 
Dut if the potatoes are raised in damp weather, it is better to spread them out on a floor, and let them dry there.

A point of great importance is to cover heaps over with a layer of straw, at least six inches thick. This layer of straw should be thickest near the ground; it should there extend beyond the heap of potatoes, so as completely to prevent the access of frost. The straw should be well filled at the summit and angles, and the whole covered up with earth. It is not, indeel, the carth which protects the potatoes from frost; this effect is produced by the straw, which prevents the radiation of heat from them; but the earth should be closely pressed to prevent the air getting through the straw. Earth which has no consistence and casily crumbles is, therefore, unfit for the purpose ; if no other can be obtained, some kind of covering must be placed over it.

A precaution rery necessary to be observed, is not to close the heaps completely in autumn so long as the weather continues warm. A small quantity of air must be allowed access through the top till the frost comes on; a vent will thus be afiorked fur vapors which rise from the heap. Covering the heaps with dung is always useless and often mischievous.

When a that comes on it is prudent to open the heaps a little at the top, to permit the escape of vapor. 


\section{HA P'I E I V.}

An Account of Disenses which hare previously affected the Potutoe, and the Remedies that have been found efficacious.

In finding materials for this chapter I mist necessarily confine my attention principally to English pulblications, as English writers on agriculture have noted and marked the nature, effects, and enre of the various diseases which have affecteri this root, with more exactness and precision than have characterized American writers on this subject.

The potatoe is subject to disease at a very early period of its existence, not merely after it has dereloped its leaves and stems, but before the germ has risen from the set.. The disease which affects the plant is called the curl, from the curled or crumpled appearance which the leaves assume when under the influence of the disease. What the immediate cause of the disease is, it is very difficult to say; but the puny stems and stinted leaves indicate weakness in the constitution of the plant, and, like weak animals affected with constitutional disease, the small tubers produced by curled potatoes, when planted, propagate the disease in the future crop. The curl is so well known by its appearance, and the curled plant so generally shumned, as seed, that the disease is never willingly propagated by the cultivator; still there are circumstances in the management of the tubers which induced the discase therein. The experiments of Mr. T. Dickson 
show, that the rlisease arises from the regetalule power of the sets planted, having heen exhausted by over-ripening. so that sets from the waxy end of the potatoe prodieed healthy plants, whereas those from the best ripencel end did not vegetate at all, or produced curled plants. It is the opinion of Mr. Crichton, that the curl in the potutese, may often be oceasioned by the way the potatoes are treated that are intended for secel. "I have olscerved," he says, "wherever the seed stock is carefully litted, am not exposed to the air in the spring, the (rop) lats rellom any curl; but where the seed stock is put into larns and not houses, for months togrether, such (cop) schlom escaples turning out in a great measure curlent; and if hut few curl the first year, it they are planted again, it is more than probuble the half of them will curl again next year:"

Mr. Knicht, on the suljeet of this discase, in an article written in 1810, silys: " A fiew years ago the curl thestroyed many of our best varieties of the potatoe, to the attacks of which every grool rariety will probahly be sulject.

I olserved that the latves of several kinds of potatoes, which were dry and farinareous, that I cultivated, prosluced curlexl leaves, whiles those of hel kinds, which were soft and aquents, were perfectly well formed, whence I was led to suspect that the discase originated in the preternaturally inspisated state of the sap in the dry and farinaceous varicties. I conerived that the sap, if not suffeicently fluid, might stagnate in, and close, the fine versels of the leaf cluring its growth anl extention, and thus occasion the irregular contractions which constitute this disetse; and this conchusion, which I diew many years ago, is perfectly consistent with the opinions I have sulserguently entertained, respecting the formation of learcs. I therefore suffered a quantity of potatoes, the produce almost wholiy of diseased plants, to remain in the heap, where they had been preserved during winter, till 
cach tuber had emitted shoots of three or four inches long. They were them earefully detached with their fibrous roots, from the tubers, and were eommitted to the soil: where laving little to subsist upon except water, I concluded the cause of the discase, if it were the too great thickness of the salp, would be effectually removed, and I had the satisfaction to observe, that not a single curled leaf was produced; thomgh more than nine-tenthe of the plints, which the same identical tubers subsequently produced, were much diseared.

In the spring of 1808 , Sir Joln Sinclair informed me that a gardener in Scotland, $\mathrm{Mr}$. Crozer, had discovered a method of preventing the curl, by taking up the tuluers before they are nearly full grown and consequently before they became farinacens. Mr. Crozer, therefore, and myself; appear to have arrived at the same point hy very different routes; for by taking his potatoen, whilst inmature, from the parent stem, he probably retained the sap nearly in the state to which my mode of culture reslucen it. I therefore conclute that the opinions I first formed, are well founded, and that the disease may he always removed by the means I employed, and its return prevented by those adopted by MIr. Crozer.

Another discase affects the seed, and is ealled the faiture, or tuint, which consists of the dutrutetion of their vital powers. MIany conjectures hive been hazarded as to the cause of the failure, ant most of them have ascribed it to the fermenter? state of the lunger, to the drought of the season, to the leating of the sets, to the tuber being cut into seth, and other secontary causes; lut all these conjectures leave untouched

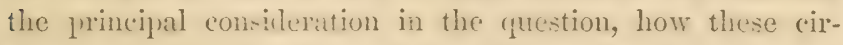
cumstances shonlel intluee failure now, and not in by-gone gears. Cut sets hare heen ueed for many years without cansing failure. Farm-yarl dung in various states of deconpusition, has heen nsed as long for raising potators. The extraturdinary drought of 1826 caused no fitilure, while in comparative cool seasons the disease has made great havoc. 
MIr. John Shirreff takes a general and philosopllical view of the cause of disease in the potatoe crop, and though, no doubt, his observations are particularly applicable to the curl, still they will apply equally well to the taint; for the connection between the two diseases is so intimate, that you have scen Mr. Dickson's observation is, that some sets "did not vegetate at all," thiat is, failed, "or produced curled plants." Mr. Shirreff adopts the general doctrine broached by Mr. Tinight. "The maximum of the duration of the life of any individual regetalle or animal," he says, "is predetermined by nature, under whatever circumstances the individual may be placed; the minimum, on the other hand, is determined by these very circumstances. Adnitting, then, that a potatoe might reproduce itself from tubers for a great number of years in the shady woods of Peru, it seems destined to become abortive in the cultivated ehampaign of Britain, insomuch that not a single healthy plant of any sort of potatoe that yields berries, and which was in culture twenty years ago, can now be produced." IIr. Shirreff conclude, therefore, that the potatoe is to be considered a short-lived plant, and that though its health and vigor may be prolongerl by rearing it in elevated or in shady situations, or by cropping the flowers, and thus preventing the plants from exhausting themselves, the only sure way to ohtain vigorous plants, and to ensure productive crops, is to have frequent recourse to new varieties from seed. The same view had oceurred to Dr. II unter, who, in his Georgical esiys, has limited the duration of a varicty in a state of perfection to fourteen years.

The faret ascertained hy Mr. Kinight duserves to be noticed. That by planting late in the seition, an exhausted good variety, may, in a great measure be restored; that is, the tuber resulting from the late planting, when again planted at the ordinary season, produces the lind in its pristine vigor and of its former size. It is obvious that all these opinions 
xefer to the possilsility of plants indicating constitutional weakness, and why may not the potatoe? I have all along been of the opinion that the failure lias arisen from this cause, nor does it seem to me to be refuted by the fict, that certain varieties of potatoe have been cultivated for many years in the same locality withont fail ; because it is well unlerstood that every variety of potatoe has not indicated failure, and one locality may be more farorable to retention of vigor of constitution than another; at least, we may easily believe. this. I have no doubt in my own mind that were seed potatoes securely pitted, until they were about to be planted,not over-ripened before they were taken out of the ground,the sets cut from the erispest tuber and from the waxy end; the dung fermented by a turning of the dung-hill in proper time; led out to the field, quickly spread, the sets as quickly dropped in it, and the drills quickly split, there would be little heard of the failure eren in the dryest season. I own it is difficult to proce the existence of constitutional weakness in any given tuber, as its existence is only implied by the fact of the failure; but the hypothesis explains many more facts than any other, than atmospheric influence, for example, producing the failure like epidemie diseases in animals, for such influences existed many jears ago, as well as now. The longer the cultivation of the tuber of the potatoe, which is not its seed, is persevered in, the more certainly may we expect to see its constitutional vigor weakened, in strict analogy to other plants propagated by similar means; such as the failure of many varieties of the apple and pear, and of the cider fruits of the seventeenth century. This very season (18t3,) contradicts the hypothesis of drought and heat as the primary cause of failure, for it has hitherto (to June) been neither hot nor dry, while it strikingly exemplifies the theory of constitutional weakness, inasmuch as the fine season of 18.12 had so much over-ripened the potatoe, - farmers still unaware of 
the cause of the failure, permitting the potatoes they hare used for seed to become over-ripened, - that the sets this spring, to repeat again the words of Mr. Dickson, "dicl not regetate at all," even in the absenee of heat and drought, and in the presence of moist weather. IIad the potatoes been a little less over-ripened in 1812 , the sets from them might hare protuced only curl this season, thongh it is not improbable that the same degree of orer-ripening may cause entire failure now, that would only have caused curl years ago; and as orer-ripening mas excessive last year, owing to the very fine weather, so the failure is extensive in a corresponding degree in this, eren in circumstances considered by most people preventive of its recurrence, namely, in cold and moist weather. And observe the results of both $18+2$ and 1843 as confirmatory of the same principle, illustrated by diametrically opposite circumstances. The under-ripened seed of the bad scason of 1811 producerl the good crop of potatoes in 1812, in spite of the great heat and drought existing at the time of its planting in 18.12; while the orer-ripened sced of the good scason of 1812 has produced extensire failure, in spite of the coolness and moisture existing at the time of planting in 1843. How can heat, drought, or fermenting dung, account for these things?

$\Lambda$ fact, may be mentioned the effects of comparatively dry and moint soil, on cut sets and whole potatoes, which were bronght to light by an experiment of Mr. Howden, and which obtained results no one would have anticipated. Says Mr. Howden:

"On the 2Sth of June I selected from a stock of potatoes which had been repeatedly turned and kept for fimily use, seventy tubers of the old rough black variety. I divided this number into five lots, sizing them so that each lot of fourteen potatoes weighed exactly four pounds. I made on that day one lot of fourteen pounds into starch, and obtained nine ounces. 
On the same day I put fourteen potatoes whole, and fourteen cut into fifty-six sets, into a decel hox, filled with diry mould. The remaining fourteen whole and fourteen cut, I put into another box filled with moist earth, and which was watered from time to time. At the end of three weeks, all the plants, with the exception of five sets, male their appearance. All this time the diry box had been kept from moisture. On the 21st of July, however, I allowed it to be moistened with heavy rain, and on the 28th of July, I took up and extracted starch from the whole. Defore doing so, however, I weighed the sereral lots, and what seemed to me curious was, that each lot of the whole potatoes hat yuined eight ounces; while each lot of the cut ones had lost six ounces of its weight, and of their number ten did not regetate. The sprouts from the whole potatoes weighed four ounces, and those from the cut only two ounces. Yet the stareh from the twentyeight eut potatoes weighed but two ounces, and that from the twenty-eight whole potatoes nine ounces, being exactly the produce in starch of half that number, which was made into starch at the commencement of the experiment."

Loudon, in his Encyclopredia of Agriculture, says: "The diseases of the potatoe_are chiefly the scab, the worm, and the curl. The scal) or ulcerated surface of the tubers, has neter been satisfactorily accounted for'; some attributing it to the ammonia of horse lung; others to alkalli; and some to the use of coal ashes. Climnge of seed and of ground are the only resourees known at present for this malady. The worm and grub both attack the tuber, and the same preventive is recommended.

The same causes which have been assigned to a total or partial failure of the potatoe in numberless instances, and to a most distressing extent in Ireland, have existed since the cultivation of the potatoe commenced, but without the effects deplored, which have only prevailed within a very recent 
space of time. But from the frequent and searching inrestigation of the sulject by the most competent and practical men, a preventive against the failure has been ascertained, namely, the planting of entire tubers. When the cut sets have failed, the entire tubers lave resisted premature decay; whether it arises from atmospheric influence or debility of constitution, or from any of the conjectured causes, the entire tubers exert their noxious influences, and germinate healthily and freely. All reports arree on this point; there is no risk in this case, if the tubers be sound when planted; and it may be added that in all stages of their growth, the uncut tubers maintain a decided superiority and yield a corresponding produce.*

In this country, the most prevailing disease that has been noticed is the rust, which, by some, is regarded as an entirely new disease, while others speak of it as haring prevailed years ago. As a general rule with us, the potatoes have been more exempted from disease than any other cultivated crop, the least liable to injury from insects, and, of consequence the most certain (rop which our farmers could cultivate. The scab and curl luce been the only known diseases in Europe, and probahly not one in a hundred of $\Lambda$ meriean cultirators ever saw an instance of the latter discase.

In 1839, the potatoe in New England found a formidable enemy in the black rust, which has caused great loss wherever it has shown itself. It has been most destructive on low lamis, sluggish streams, near ponds, or on low meadows or plains; the more elevated, airy, and dry situations, have generally escaped. The following, respecting this new disense, is from the Farmer's Monthly Visitor, and I invite particular attention to this account, and the olservations which follow, as I beliere it will be found closely allied to

* Dictionary of the Farm, p. 413. 
the Potatoe Plageuc, which will be fully described in Pirt II, of this treatise:

"The cause of the rust this season, (1839) we beliere to be the extraordinary lumidity, combined with a peculiar state of the atmosphere, at some period in the lighh heat of summer. It was remarked that the rust struck universally on the 27 th of August. Early planted potatoes were not so much injured by it as the later erop. Last year, it will be remembered, the severe drought in that part of the country south of a line drawn east and west, at the distance of fifty to serenty miles north of Boston, generally lessened the crop of potatoes, affecting those early and late planted in a similar manner that the rust has this year injured them. It was too dry last summer, and the uncommon wetness of the present summer has been alike injurious. More than half the days in June, and tro-thirds the days in July, and one third in August were rainy days. In a season so uncommonly wet we could not but anticipate quite as much injury to some crops as we have suffered. The benefits to the grass crop and small grains, have amply compensated for every thing."

In 1841, a correspondent of the Maine Farmer wrote ats follows :

"Almost all persons with whom I have conversed on the subject ascribe the failure of the potatoe crop to rust; and I know very well the tops have a rusty appearance, while some few have mentioned other causes. I have had ample time and opportunity to examine numerous fields under all the different circumstances of soil and culture, and time of planting, which could be found, and the result in my mind was satisfactory that no single cause assigned could alone produce it. In one field, planted partly with the pink-eyed variety, and partly with the long recks, the pink-eyes were so dead, the tops, on pulling, broke off, without pulling up the potatoes, and the owner had commenced digging. The long 
reds growing side by side appeared as fresh and fair as ever', to a casual inspection. But on closer examination the leares at the bottom were dying, and the same process of decay appeared to have commenced, hy which the pink-eyes - Bierl. It is said the sap which forms the potatoe is elaborated in the leares, and I believe this is not doubted by any physi-ologrists; but how can this fact be reconciled with the fact that some varieties are quite as large as usual, and the assigned cause of rust we have mentioned.

"From all the olservations I could make there seems to have been some general cause operating, from the time of the blossoming of the earliest variety, and the earliest planted to the latest, by which the formation of the bulbs was restricted to few in number. This cause, I am constrained to believe, is atmospheric."

$\Lambda$ work has lately been published by Dr. Tan Martius, on the epidemic diseases of potatoes. He enumerates all the diseases that have been observed from time to time, and describes more particularly two forms which did extensire damage to the potatoe crops of Germany, in 1841. These he calls, in literal Euglish, stem rot, scab. It is to the first of these discases that we wish to call attention, as resembling, in many of its symptoms, moist gangrene. There is, lowever, this difference between that disease, and the one we are about to mention, that the former attacked only leaves and fruits, and was accompanied by the presence of a large quantity of moisture, whilst this attacks the tuber, an underground stem, and is characterized by a diminution of water in the tissue of the plant. It is, in fact, a dry gangrene, and Martius calls it Gangrena tuberum Solani.

When potatoes are attacked with this disease, the first thing that is observed is, a drying up or shrivelling of the tuler. The skin loses its ordinary lustre, becomes wrinkled, and shows at last little irregular spots, of a dark brown color, 
which, as the disease progresses, run together into larger spots. In these places the skin seems thicker, and has the appearance of having been rubber against something. Subsequently, the tissue of which the skin is composed becomes loosened and torn; and by the breaking up of its continuity, it assumes the appearance of the back of an old tree. Sometimes the skin is split up into distinct patches, like seales; at the commencement of the disease the interior of the tuber does not suffer; but, at last, a cliange of color takes place in the tissues under the spots of the slin. Patehes of a yellow, or hrown color, are observed, which are at first isolated, but at last run into one another. These patches are drier than the surrounding tissue; but up to this period in the appearance of the disease, no changes have taken place that render the tuber unfit to eat.

As the disease adrances, little warts, or excrescences, form on the skin, which are of a dark color inside; they are at first small, but keep on extending, and at last run one into the other. From the surface of these warts, a fungus, belonging to the mould of the potatoe tribe, is observed to project. The potatoe now begins to emit a disagreeable odor, and its physical character is greatly changed. Its specific grarity, which, in a state of health, is 1.103 , hecomes successively reduced, as the disease proceeds, and at last is aloont 0.9. If potatoes are planted with this disease, in no case do they put forth healthy shoots. In the commencing stages, the eyes put forth shoots which rise abore the ground, but soon perish. In the latter stages the whole tissue of the potatoe is inrolved in disease, and on cutting into it, it presents a dark colored, disorganized mass, very dry, and not unlike the appearance of a truffle.

On examining the tissues unter a microscope, it will be found that the cellular tissue of the skin lias lost its transparency, and become of a brown color, and that of the in- 
terior has lost its brightness as well as its moisture and whiteness. The starch grains gradually disappear, and cells filled with air, and a yellow fluid, vecupy their place. Many cells are torn, and the passages are filled with a brown fluid.

Scattered between the cells in all directions will be found dark colored, opaque grains of rarious forms and sizes. These grains do mot derelope any further, but at last burst, and in their appearance and history rescmble the Protomyces, or primitive fungus germs of unger. On cutting into the little knobs, masses of the fibres of a fungus are observed, which at last make their way to the surface, and there either fructify or become slurivelled into a whitish layer. Sometimes the filures of this fungus, which are very delicate and transparent, are found throughout the whole mass of the diseased tuber. On examining these fibres, they present two distinct forms, the one being probably a variety of the other.

I am not amare that this form of disease has prevailed very extensivcly in this comntry. With regard to the cause of the discase nothing certain is known. In Germany it has occurred in all soils and in all weathers. It has occurred to almost all sorts of potatoes, and after all modes of planting and gathering; so that many have been inclined to attribute it to the influence of contagion; whilst those who are advocates of the doctrine that all diseases arise from the sporules of fungi, will at once conclude that the influence of the fungus in this disease is a proof that it originated in their presence. For the precention of this rot erery precaution should be taken in planting them to secure their healthful growth. The conclusions of Ton Mrartius are as follows: The newer the rariety is, the better. The potatoes intended for seed should be grown separate from the rest. The secl potatoes should not be kept heaped up in damp cellars, and allowed to shoot iefore they are planted, and they should nerer be cut for sowing before they are brought into the field. 
I conclude this part of my sulject, ly extracting the following article by MIorrill Allen, an intelligent, practical farmer, of Missachusetts. The extract properly belongs, perliaps, to Part II, of this work, but it is also comnected with the present chapter. IIe says: "There have been sufficient indieations of the existence of disease, and advances, to justify some general attention to the sulject, and the employment of such freventive, or remelial means, as may seem to cultivators the most likely to prove efficacious. Until the catuses of the malady shall be more satisfactorily investigated, no rules can, with implicit confidence, he giren for the treatment. The farmers must do as physicians are sometimes obliged to do in cases of untefined bodily disease, - prescribe to the symptoms. This practice is attended with great uncertainty, yet the results, of it in experience sometimes prove highly valuable. The different canses to which the clisease in potatoes has been ascribed, lead writers to suggest a great rariety of remedies in accordance with. their views of the probable origin. Let farmers select and apply such as their reason and judgment best approve, and it may be that merely practical men will, in the course of their experience, clearly prove what theory has hitherto failed of doing, the moring cause of the difficulty. If, as supposed by some, it be of insect origin, then salt and lime would seem proper applications, and these are also strongly recommended by persons who think that fungus is the producing cause of the disease. Those who suppose it arises from atmospheric influence may properly apply the same means which would be recommended by those who believe it the result of excessive growth. Preparation of the soil, and a course in the cultivation likely to produce an even growth is unquestionably important in this and other crops. Some persons seem confident that the rot in potatoes results wholly from deterioration in the seed. If this be true we may not expect to aroid 
the eril merely by sending to another place for seed potatoes; we should renew them from the balls. This is a process requiring some patience, but we know of no ensier method of entire renovation. We stppose renewal can be approached in successive plantings of ummatured potatoes. These have often been strongly recommended for seerl, not only for the jurpose of aroicling disease, lut as a means of increasing the crop. It is manifistly contrary to what we regarl as a general law in vegetation, that the most perfect seed produces the healthiest and most fruitful plants. There are, liowever, several reasons for believing that the potatoe may be an exception to the general law. The regetative principle is not so concentrated in the potatoe as in most other articles. It can be produced from the balls, the bulbs, or from sprouts which have grown in the cellar, or the earth. The regetatire principle being so widely diffused, it may be reasonable to suppose, that the perfect ripening of the potatoe to some extent weakens its power of reproduction. 'That power after the complete maturity of the bulbs may be more perfectly concentrated in the bills. The experiment is easily made, and it is hoped that many farmers will this year plant potalnes for. the next year's sceding as late as the 255 th of June:" 


\section{H A P T E V V.}

Turious Lses to which Potatoes are applied.

Tre most important application of potatoes is as human food; on this it is unnecessary to enlarge.

Einhoff found mealy potatoes to contain twenty-four per cent. of their weight of nutritive matter, and rye seventy parts; consequently sixty-four and a half measures of potatoes afford the same nourishment as twenty-four measures of rye. A thousand parts of potatoes yielded to Sir Humplirey Davy two hundred to three hundred parts of nutritive matter, of which one hundred and fifty-five to two hundred were mucilage or starch, fifteen to twenty sugar, and thirty to forty gluten. Now, supposing an acre of potatues to weigh nine tons, and an acre of wheat to weigh one ton, which is about the usual proportion, then, as one thousand parts of wheat afford nine hundred and fifty nutritive parts, and one thousand of potatoes say two hundred and thirty, the quantity of nutritive matter afforded by an acre of wheat and potatoes will be nearly as nine to four; so that an acre of potatoes will supply more than double the quantity of human food affordecl by an acre of wheat. The potatoe is, perhaps, the only root grown, which may be eaten every day in the year without satiating the palate. They are therefore the only substitute that can be used for bread, with any degree of success. In the answer by Dr. Tissot to M. Linquet, the for- 
mer objects to the constant use of potatoes for food, not because they are pernicious to the body, but because they hurt the faculties of the mincl. IIe owns that those who eat maize, potatoes, or even millet, may grow tall and acquire a large size. It does not, however, by any means appear, that the general use of potatoes has imprired either the health of body or vigor of mind of its inhabitants.

The manufacture of potatoe flour is carried on, to a considerable extent, in the neighborhood of Paris, and the flour is sold at a price considerably higher than that of wheat, for the use of confectioners, and of bakers who supply the finer kints of bread. The potatoes are washed and grated, and the starch separated from the pulp so attained by filtration; it is dried on shelres, in a room heated hy a flue, and afterwards broken on a floor, by passing a cast iron roller over it. It is then passed into a bolting machine and put into sacks for sale. It is reported by Count de Chatrol, in his statistical account of Paris, that forty thousand tous of potatoes are annually manufictured into flour within a circle of eight leagues around the city.

The quantity of farina which potatoes produce raries not only according to the species, but according to the period when the extraction takes place. The variations produced by this last cause are nearly as follows:-

Two humelred and forty pounds of potatoes, produced of farina, or potatoe flour, in

$\begin{array}{llllll}\text { August, from } & 23 & \text { to } & 25 & \text { pounds. } \\ \text { Sept., " } & 32 & \text { " } & 38 & \text { " } \\ \text { October, " } & 32 & \text { " } & 40 & \text { " } \\ \text { Nov., " } & 38 & \text { " } & 45 & \text { " } \\ \text { March, " } & 45 & \text { " } & 38 & \text { " } \\ \text { April, " } & 38 & \text { " } & 28 & \text { " } \\ \text { May, " } & 28 & \text { " } & 20 & \text { " }\end{array}$

The extraction of the farina should be discontinued at the 
period when the potatoes begin to grow, the farina being destroyed by germination. lied potatoes produce a smaller quantity of farina. Those which are blue on the outside give little, but it is of good quality ; the white, which is often tinged with red in the interior, is the least proper for this extraction. The best of all are those which have a yellow tint, as the furina is of very good quality and abundant.

The meal of potatoes may be preserved for years, closely packed in barrels, or unground in the form of slices, these slices having been previously dried by steam. Some German philosophers have proposed to freeze the potatoes, by which the feculent matter is separated from the starch, and the latter being then dried and compressed, may be preserved for any length of time, or exported with safety any distance.

The manufacture of tapioca from potatoes is thus given in the Quarterly Journal of A griculture. The potatoes selected are thoroughly washed, afterwards they are grated in a machine constructed for the purpose. The parts thus reduced or grated fall into a ressel placed underneath. From this vessel they are removed, and strained into a tub. On the juice being well expressed for the first time, the fibrous matter is set apart, and cold clean water is thrown over them. The fibres are again put through the same strainer, till the whole of the substance is collected, when they are finally cast aside. On this being done, the contents of the tub, now in a state of mucilage or starch, are allowed to settle. A reasonable interval being suffered to elapse, the old water is poured gently off, and fresh water supplied. After this process of washing the bleached matter is passed through a smaller strainer.

The offals are separated; the starch now becomes much whiter; but still fresh water is abundantly dashed over it. When by frequent ablution the surface of this mass is rendered quite smooth and clear, it is filtrated a third and list time. 
The strainer now used is of very fine texture, so that no improper or accidental admixture may interfere. As soon as the starch thus purified, has firmly subsided, it is spread on a board, and exposed to the open air. The damp speedily evaporates, on which it is, as a security for cleanliness, put through a sieve.

A large circular pan is now procured, and set upon the fire. The farina is gradually put into the pan, till what is conceired to be sufficient for one cooking has been supplied. As the natural tendency of the farina, in a warm state, is to adhere to the pan, great care is requisite in constantly turning and stirring it. This is effectually done with a broad flat piece of wood, having a long handle to prevent inconvenience from the heat. A temperature of one hundred and fifty degrees, Fahrenheit, suils best for perfecting the tapioca. When the farina becomes quite hard, dry and gritty, it is then ready, and may be taken off the fire.-Quarterly Journal of Agriculture, Vol. $I I ., p_{0} 68$.

Potash may be extracted from potatoe leaves and stalks, by the following process:- Cut off the stalks when the flowers begin to fall, as that is the period of their greatest vigor; leave them on the ground eight or ten days to dry; eart them to a hole dug in the earth, about five feet square by two feet deep, and then burn them, keeping the ashes red-hot as long as possible. Afterwards take out the ashes, pour boiling water on them, and then evaporate the water. There remains, after the evaporation, a dry saline reddish substance, known in commerce under the name of satin; the more the ashes are boiled, the greyer and more valuable the salin becomes. The salin must be calcined in a very hot oren, until the whole mass presents a uniform reddish brown. In cooling it remains dry, and in fragments bluish within, and white on the surface, in which state it takes the name of potash. Smith's Mechanic, Vol. II., p. 381. 
Among extraordinary applications of the potatoe, may be mentioned cleaning woollens, and making wine and ardent spirits.

Cleaning Woollens. - The refuse of the potatoes used in making starch, when taken from the sieve, possesses the property of cleansing woollen cloths, without injuring their color; and the water decanted from the starch powder is excellent for cleansing silks, without the slightest injury to the color.

Wine and ardent spirits of a good quality are made from potatoes. Under the influence of certain chemical agents, which it is not my province here to speak of particularly, starch is converted into sugar, and this sugar, by fermentation, yields spirits. On the European continent potatoe spirit is almost universally used; and in flavor it so resembles brandy that it is well known that a large quantity of the French brandy brought into London, is potatoe spirit from Hamburg, colored with burned sugar.

On converting potatoes into flour, $\mathrm{Mr}$. Abiel Abbott, of Sidney, Me., thus writes to the Kemebee Journal:

"After much study and many experiments, I have made a discovery which I think will, with that encouragement it merits, be of great importance to the people of this state and all others similarly situated.

"In 1832 I was strongly impressed that flour might be obtained from the potatoe; accordingly I ventured an experiment, the result of which was, eight pounds of flour from the bushel. I then suspended my experiments until the winter of 1814, when I resumed them, and found the result to be the same as 1832, that is, eight pounds of fine flour from the bushel. Owing to a deficiency of gluten good bread cannot be made from it alone, but when mixed with equal parts of wheaten flour, the bread made from it is much better than that which is made from all wheaten flour, - that is, in the estimation of those who have eaten the bread. 
"Two hundred bushels of potatoes to the acre, is called by the firmers an arcrage crop in Maine, yielding, according to the foregoing experiments, about eight barrels of flour to the acre."

The following article, extracted from the last number of the Journal of the Royal Agrienltural Society, will be found interesting in this connection:

"In Germany, a method has lately been introduced, of making flour from potatoes, which has not, I beliere, been tried in this country, but which is recommended as giving a better, a more palatable, and a more abundant article of nourishment than the common process of preparing potatoe starch. This method consists in washing the potatoes, cutting them into slices, as we do turnips, steeping these slices for twenty-four hours in water containing one per cent. of sulphuric acid, (oil of vitriol) drawing off the acid water, washing them several times with pure water, drying them in a stove, and then grinding them in a common corn-mill. The flour thus obtained is pure white, and the refuse siftings or bran, seldom exceed five per cent. of the weight of the dried potatoes. The sulphuric acid in this process extracts the coloring matter of the potatoe, with certain other substances which would give the flour an unpleasant taste. This flour will not make grood bread if used alone. It requires to be mixed with from one-half to one-third of wheaten flour."

But the following is the most interesting piece of informafion that we have met with on this subject. It refers to the most economical method of using the potatoe crop as food for eattle:-

"As I have saicl so much on the subject of potatoes, I may as well describe to you a methor which has lately been recommended in Denmark and Norway, for making the potatoe more arailable and more profitable in feeding cattle than it has ever hitherto been. You are probably aware that potatoe 
starch can be readily converted into grape sugar, and that the syrup obtained from it is largely employed for the manufacture of brandy in the north of Europe, and even of the best brandy which comes from France. In the more northern of the French wine-growing provinces it is also mixed with the less sweet raricties of grape juice, so as to give an additional strength and richness to the wine. One of the methorls by which the potatoe starch is converted into grape sugar, is to mix it with one tenth of its weight of ground malt diffused in water, and to keep the mixture for some hours at a moderate temperature. The starch dissolves, and the liquid becomes sweet from its conversion into grape sugar. This is the method which MI. Bïgrilt, of Copenhagen, proposes to apply to the whole potatoe, in order to bring it into a soluble state, to make it more easy of digestion, and thus to increase its feeding properties. IIe washes his potatoes well, steams them thoroughly, and then, without allowing them to cool, he euts them in a cylinder furnished internally with revolving knives, or crushes them in a mill, and mixes them with a small quantity of water and three pounds of ground malt to every one humired pounds of the raw potatoes. This mixture is kept in motion, and at a temperature of one hundred and forty degrees to one hundred and eighty degrees Fahrenheit, for from one to five hours, when the thick gruel has acquired a sweet taste and is ready for use. Given in this state, the results of experimental trials are said to be -

"1. That it is a richer and better food for milk cows than twice the quantity of potatoes in a raw state.

"2. That it is excellent for fattening cattle and sheep, and for winter food: that it goes much farther than potatoes when merely steamed; and that it may be economically mixed up with chopped hay and straw.

"I have before me a pamplilet, published at Christiania, by the Royal Society for Promoting the Improvement of Nor- 
way, in which this method is strongly recommended; also a letter from Copenhagen, dated 29th April, 18t5, in which my correspondent writes as follows:- This invention has been more and more appreciated and applied in my native country (Norway) and in Denmark, and the great advantages with which stall-feeding may be introduced, at considerably less expense than formerly, render it suited to general promulgation.' - 'The method has more and more gained adherents, and further comparative experiments, made by scientific and experienced persons, have proved its superiority. Thus one of these experiments establishes that an increase of one and a half pounds of flesh is obtained from twenty-five pounds of potatoes - that the feeding of horses with this mash is found to be applicable and cheap, and they all confirm that potatoes used in this manner as food amply aftord double the nutritive powers compared with the food formerly used.' I camnot here state my reasons for believing that there is really something worthy of attention in the alleged superior feeding qualities of the potatoe given in this state; but I can strongly recommend you to make experiments upon this subject. If the potatoe can in this way be converted into a larmer (1uantity of beef, mutton, or pork, than hitherto, another outlet will be provided for the potatoe erop, which may, perhaps, prore more profitable even than the manufacture of it into flour." 


\section{P A R T I I.}

\section{THE POTATOE PLAGUE.}

\section{Preliminary Remarks.}

IN the preceding pages I have collected important information on the history, cultivation, diseases and uses of the potatoe. I commend that part of the book to the candid attention of the farming community, as it contains much that is new. The views of MI. Thaer, especially, now for the first time republished to American readers, will claim their attention as being the mature experience of a distinguished cultivator, after years of observation into the nature of the tuber and the best modes of managing it.

I now approach the great sulject of this treatise with unfeigned diffidence. I would, in the outset, deprecate criticism, by the confession, that the material portions of information contained in these pages are not from my own knowledge, or the result of my individual experience. The work is composed of better materials than any one farmer or scientifie cultivator: could possibly furnish, were he even the most profound and practical in the land. It is a condensation of the opinions of farmers and scientific men from every part of this country and Europe, respecting every variety of the potatoe, 
grown under every variety of treatment, soil, and temperature, and under every possible change or rariation that can be supposed with reference to it.

It is almost impossible to orer-rate the importance of an Inquiry like the one we are about to make. Its influence upon the prosperity and wealth of nations may he gathered from the fact that the potatoe crop of the United States alone is estimated at ninety-nine millions nine hundred and forty-three thousand bushels annually, and in New England it is thus stated by Mr. Ellsworth, in his report to Congress, in January, 1845 .

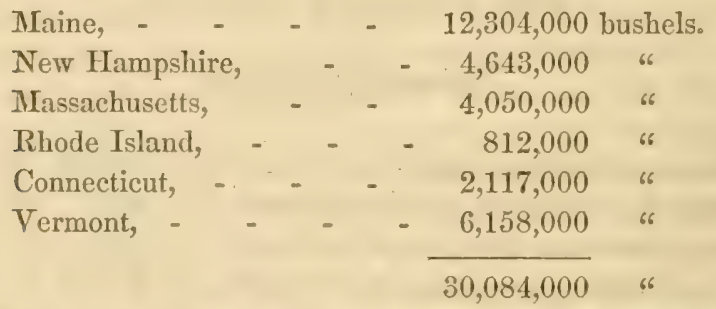

Thus it will be seen, that the erop in New Fngland, at a low estimation, is worth ten millions dollar's annually, and the rot threatens, if not the total desertion of this larese source of productive wealth, at least a rery great diminution of the profits of the farmer, and a decrease much to be dreaded in the supplies of the most healthful, as it is the most universal, article of food for human consumption.

It was hoped in 18.1, that the disease had reached its culminating point, and that the jear 1845 would witness a great falling off in its destroying effects, and that, like the Asiatic Cholera, and other similar diseases affecting the human constitution, it would disappear and be heard of no more.

This very desirable consummation, however, was not realizerl. The rot has prevailed more extensively this year than ever before, and not only throughout the wide extent of 
our own country are the eomplaints of entire failure or partial destruction heard, but the voice of lamentation and the fear of famine come to us with a foreboding moan from the British isles, and some of the countries of continental Europe. The rot this year has been universal in its effects, and the exigency has called forth particular and anxious inquiries into the nature of the disease, accounts of which, and the results arrived at, are subjoined.

It woukl, perhaps, be diflicult to name a subject on which more has been written, or which has engaged the attention of more able men than the prevalent potatoe blight, rot, or by whatever name it may be called. The plague and the yellow fuver have not been more anxiously discussed; nor can it be denied that the subject is of almost equal importance. A calamity that involves the destruction of a great portion of the food and labor of the civilized workd, and reduces millions of fellow-creatures to literil starvation, camnot be too diligently studied; if, lappily, thereby, the evil may be averted, checked, or in any considerable degree lessened. It is estimated by those more competent to form an estimate than I can pretend to be, that-three fourths, at least, of the potatoe crop of all Ireland will have been lost the present season. Supposing that the potatoe is the principal food of only four of the millions of that wretched country, what an amount of human suffering does the prospect present.

I find, by a careful comparison of much that has been written on this interesting topic, that most of those who have made it a subject of inquiry, have fallen into the common error of generalizing too much, of deducing the rule from the particular instance, instead of tracing wherein the instance has coincided with, or deviated from, the rule. Now, there are countless varieties of the potatoe, and to suppose that the treatment which has succeeded with one, or two, or a dozen of these, is the one only means to be: used with regard to the 
whole family, however plausible or natural such decluction may be, is certainly not the way in which scientific knowledge has been brought to its present degree of perfection. Because a certain mole of treatment has proved beneficial to a Iymphatic inlabitant of the aretic circle, in a particular disease, does it follow that the same mode would produce the same result on a sanguine or bilious temperament between the tropies? Does it follow that the same laws and government to which New England quietly submits would be fitting for the island of IIayti, or one of the psculo South American Republics? Yet this is the process of reasoning and induction that has been applied almost universally to the culture of the potatoe.

One writer has tried one or two varieties of the root in certain soils and situations; he has applied certain manures and a particular treatment of his own, and he therefore argues that what has sueceeded or failed with his variety will be equally successful or otherwise, with the whole potatoe family. This is, to the multitude, very plausible and comfortable doctrine; they adopt it, and suffer, because they have not discovered that the coat that fits a tall, thin man, will not fit a short, thick one, of equal wreight.

We sometimes find, in investigating the reports of scientific men, that the same variety, planted and dug at the same season, from the same soil, and having received the same treatment, in short, as far as luman sagacity can discern, having had precisely the same advantages and disadvantages, has shown rery different results. In one field, the crop is healthy and abundant; in another, it is scant, defective and diseased. The reader will find many instances of this kind by referring to the report of the Commissioner of Patents to the twenty-eighth Congress. What, then, is the inference? Clearly that the disease is owing to some cause independent of culture, or soil, or weather, or atmospheric influence; that, 
I think, must be plain to every eapacity. Neither is the detriment likely to have arisen from the presence of fungi, infusorii, or insects, where nothing of the kind has been discovered by the most rigilant observation. Indeed, it seems to me a death blow to either of these theories, that, in very many instances, the disense has broken out after the roots were dug, apparently in a sound and healthy condition, as well as the stalks. One cause remains; an obvious, if not the only one - the difference in the quality of the seed planted, of which I shall have more to say in auother place.

It appears to me that there are many causes to which the failure of the potatoe crop the world over, may be attributed, without supposing any specifie disease, epidemic, or malignant influence whatever. The blight assumes different appearances in different climates and regions. In some parts of Germany, the diseased potatoe becomes hard, like a stone, so that it requires considerable foree to break it with a hammer; in other parts it has been observed to turn fibrous and woody, or withered, or watery, or to turn into liquid putrefaction. Can it be that all these appearances are but different forms of one and the same disease?

Every one who knows what a potatoe is, knows that all kinds of potatoes do not bear the action of boiling water alike. One kind comes from the lettle watery or waxy, another mealy; one requires twice as much time in cooking as another. Those who eat know not the cause; but they know that it is so. They are satisfied to say that it is a good or a bad potatoe, and to eat or fling it away; and they often come as nigh the fact without investigation as they could have done with it. The truth is, that it is not owing to culture, soil, or disease, that the fruit so turns out; it is the nature of one varicty of potatoe to be watery, and another to be mealy; and we conld not make it otherwise were we to study a thousand years. 
I have said that many theories have been broached in regard to the supposed potatoe epidemic. Most of them are entitled to respect, as the results of the laborious investigations of ingenious, learned, or practical men; and I shall therefore briefly notice a few of them, with such comments as they appear to me to require.

The first of these theories attributes the rot to too early or too late planting and digging. There is no doubt, in $\mathrm{my}$ mind, that either of these causes will injuriously affect a crop; the failure on a field, or a furm, may justly be referied to either or both of them. It needs no ghost to tell me that green fruit is unwholesome, or that, if allowed to hang too long on the tree, it will rot; but these causes are altogether insufficient to account for a decay extending orer all christendom, of many years duration, and of continually increasing progress. It cannot be that all, or even a great portion of those interested in the cultivation of the potatoe throughout the world, plant too late or too early, or fail to gather and store the harrest in its season. This theory will do, therefore, for a district, but not for the whole temperate zone.

The same reasoning will hold good of the effects of soils, manures, and seasons. These have their influences; they are partial and local; but any considerable and general failure may be prevented by care. It is hardly credible that they, or any of them, shoult, for a long series of years, exert the same baleful influence, every where. Besides, if this were the case, would this influence be confined to the potatoe alone, of all the vegetalle kinglom? Do we hear of any epidemic or general disease of any other regetable? We do, indeed, hear, now and then, of a failure of the beet crop, or the crop of apples, here and there; but the next year makes all right again, and if fruit fails in New England, we get it from New York and Jerecy. The world is not an Egypt,. 
where the entire vegetation may be destroyed by too wet or too dry a season.

These attempts to trace a general effect to partial causes appear to me very like the deductions drawn from the pretended rules of phrenology. I examine a stranger's head, and find the bump of destructiveness, for example, fearfully prominent. I therefore pronounce him a dangerous per:on; but, on incuiry, I learn that he is a man of remarkably benign and quiet temperament. "That." says the phrenological theorist, "is because his organs of benevolence and reverenco are equally dereloped, and neutralize his destructiveness." What practical use can be cut out of a science that defines no limits or proportions?

In like manner, "one intelligent farmer (we quote from. the report above mentioned,) on his own farm, where the soil was porous, lost none of a crop yiehling two thousand bushels; while of a field he purchased on a neighboring furm, whero the soil was clayey, and retained much water, he lust the greater part of the crop." Hence he argues that the soil and season together caused the injury, and so, undoubtedly they did; but, supposing there had been a drouth, the seed planted in clay must have fared best. No general rule can be deduced from any such suceess or failure. From this and tho concurrences of many other like instances, however, I draw the inference that a light soil is more congenial to the potatoe family, generally, than a heavy one.

Another set of theorists attribute the potatoe disense to. flies, or other insects. These, however, as far as satisfactorily observed, appear to be rio other than have been always found upon the potatoe, without producing any injurious effects. They are the common aphis or vegetable louse, and flies which confine their ravages to the leaves. It might be argued in favor, or rather in disfavor of these parasites, that, by injuring the leaves, they deprive the tuber of its proper 
nourishment; but this will not at all account for the decay of roots dug in an apparently healthy state, after being stored. Again, we have a goodly array of proofs that insects of different kinds are found in the diseased potatoe, both in the tops and the tubers; but it is by no means sure that they are the cause of the disease; on the contrary it seems highly probable that they are generated by it. This theory has, comparatively, few supporters, and does not seem to be considered entitled to much consideration by the learned in such matters.

A third theory, of which Doctor ITitcheock, of Amherst, is the most prominent supporter, attributes the universal sickness of the potatoe to "atmospheric agency, too subtle for the cognizance of our senses, like those which bring such epidemics as the influenza and the cholera over particular districts or continents? Modern science," he adds, "has shown us that many of the most powerful ageneies of nature are concealed from common and even acute observation. May there not be others, yet undiscovered, which deeply affect the delicate machinery of organic life?"

Aye, truly may there; and there may be a sixth sense, and a measure to infinity, and a limit to time and eternity. It is much easier to ask than to answer questions, and, when they relate to things confessedly beyond or above human intelligence, it is hardly worth while to ask them. There may, nay, there must be a cause for the yellow fever, and the cholera, and the potatoe plague; but if it is not within the capacity of the senses, it is hardly worth while to grope for it. I do not mean to underralue inquiry, of any lind; but it seems to me that it is time enongh to seek the transcendental causes of an effect, when the visible, tangible, and palpable ones have been thoroughly examined. It is not proved, there is no evidence beyond conjecture, that yellow fever or cholera is dependent or consequent on atmospheric agency; 


\section{The Potatoc Plague.}

neither do I see any reason even to guess such a cause of the potatoe plague.

$\Lambda$ great number of experimentalists contend that the potatoc rot is attributable to the fermentation of animal manure, and it strikes me, forcibly, that the rapid, malignant rot of a great proportion of the lost crops, may justly be attributed to this cause. More instances where the result of this mode of treatment has proved fital to the plant are adduced than of any other. I cannot altogether withhold credence from such a mass of concurrent testimony. Wherever potatoes have been manured with animal matter, and especially barnyard manure, in the hill, and when they have been planted before such compost has been allowed to disintegrate and assimilate with the soil, the rot seems to have been the inrariable consequence. On the other hand, it appears that the disease seldom appears on rirgin soil, or newly broken sward land. I the more incline to the belief that this theory is more extensively corroborated in practice than any of those $I$ have thus far noticed, from the fact that, of the potatoes treated with animal manure, those which lie nigh the outside of the hill are found best and soundest, while those in the centre, among the manure, are most specked and rotten.

It is not conclusive, howerer, that the disease can be stopped by planting on new or sward land, inasmuch as potatoes dug from such land sound, have often been found to rot after storing, so as to have been entirely lost before spring. Neither does this solution of the mystery sufice, even partially, to account for the extent of the injury in other countries; for we do not know how potatoes are manured there, or whether they are manured at all. All that can be predicated on the evidence before us is, that manuring with new animal matter is calculated to cause loss and injury.

There is yet another theory that I feel bound to notice in this connection, inasmuch as it is adranced by a rery intelligent gentleman, (Mr. Teschemacher, of Boston,) as the result 
of a series of scientific experiments made by him. He has detected in the potatoe the growth of a fungus analogous to the mushroom family. It is usually seen as a green mould, and is often found in the cores of apples and the interior of nutshells. The seeds are invisible to the naked eye, easily carried about by the wind, and penetrate wherever the air can enter. Their extensive dissemination is, therefore, easy. When they fall on the potatoe, in circumstances farorable to germination, the blight, or decay, is the consequence. The dry rot in timber proceeds from an analogous cause.

Though maintained by sereral learned men, I do not deem this theory a very probable one. It is rather difficult to conccive a fungus alichliting on the tops of a plant and thence growing its subterranean way downward to the tuber; and, when arrived there, if it ever does so arrive, there is no conclusive testimony that it produces decay. That a parasite vegetable can live and propagate itself in the capillary vessels of another vegutable, is a supposition extraordinary, to Eay the least; and, if it descend the outside of the stalk to the tuber, how does it penetrate the skin and first appear, where one would naturally least expect to find it, in the heart of the potatoe? This theory has, at least, the merit of novelty, to recommend it; but I cannot concede it my belief without further evidence. It appears to me nuch more likely that the potatoe fungus, like the supposititious potatoe fly, is an accessary after the fact; a consequence, and not a cause of the disease.

There are other some, who ascribe the potatoe plagne to the occurrence of a honcy dew, a thing which, it appears, was known to the ancients; but is certainly so little known to the molerns that I am sure they will not take it as an affront that I tell them what it is.

Early in the mornings of May or June, after a long dronght, in Carolina, and after a succession of warm days and cool nights, there is found on the leaves of plants a fluid like 
diluied honey, transparent, and tasting like the syrup of refined sugar. It thickens as the sun rises, and ceases to be fluid by ten or eleven o'clock.

I leave it to the reader's ingenuity to discover how the honey dew of Carolina can anlict the poor potatoes of Yankeedom, where it has not been seen for a liundred years, if erer, and how a disease that originated thirty years ago, in Europe, certainly, and probably in Ireland, should at last have found its prinal cause among the alligators of North America. This theory seems to me too absurd to demand serious refutation.

Having now stated what I believe but partially and what $\mathbf{I}$ do not believe at all, the reader is, perhaps, desirous to know what I do believe. I say, I have no theory but nature's, but that which is consistent with experience and common sense, but that will account for the potatoe plague, in all its phases, whenever and wherever it may appear; and which, while it detects the cause of the disease, also prescribes the remedy.

But, firstly,

There are some things certain, for which I ask no man to take my word, and which it may be of advantage to all to learn, viz:-

1. The disense is not confined to any particular kind of soil or to any locality. Some assert that it pertains exclusively to dry soil; others as stoutly maintain that it belongs only to wet.

2. It does not exclusively affect any particular kind or kinds of potatoes.

3. The affected potatoes, like other diseased regetables, are unwholesome, if not poisonous.

4. Decomposition proceeds more rapidly among the infected potatoes, when placed in a heap; whence $\mathbf{I}$ do not infer, as many others do, that it is best to defer digging till late in the Fall. 
It is an undenied, uncontroverted, uncontrovertible and undeniable fact that, in both the animal and vegetable kingdoms, between which there is a close analogy, cvery stock propagated for a long course of years within itself, exhausts Iits vital energies and deteriorates. This has been known to all nations, in all ages; this is the reason of the wise prohibition of the intermarriages between near relatives; this is the cause of the deterioration of most of the reigning families in Europe; and lence it is that there are no more heroes among the Bourbons, or wise men among the Guelplis. The intermarrying cretins and cagots have transmitted their tainted blood to a race of dwarfs and idiots, and - but why need I multiply instances? - crery practical farmer and sportsman knows the incritable consequence of "breeding in and in," and breeding from defective specimens. Ind this deterioration is as true and certain in the regetable lingdom. The scrub onks, and dry, short grass of the western prairies attest it. That the potatoe is not exempt from this inherent tendency to deterioration, I shall cite two, among a thousand evidences.

For thirty years, or more, this disease has been making slow and insidious progress in Europe; but it is not until quite lately that it has excited any alarm on this continent. What does this show, if not, that the old stocks of Europe, having had time to exhaust their vital energies, have at last fallen into inevitable decay, which is but beginning among the younger stocks of America? The once famous apple potatoe of Ireland, for a long series of years the pride and boast of the island, at last showed such signs of deeay that the cultivation of it was entirely abandoned. This liappened some years ago, and the rest of the Irish stocks appear to be now further advanced in the same progress.

In another famous potatoe growing country, Nova Scotia, the progress of the discase, and its arrest, speak rolumes in 
proof of the truth of this theory. For many years it pervaded particular finms, sometimes appearing in the stalk, long before the potatoe hat arrived at maturity; sometimes after it was harvested and put into the cellar. and what shows conclusively that this was caused by reproducing from the same, and from defective seed, is, that after inelfectually trying many other remedies, the suffering firmers hit upon the true one. They planted the balls, and thus proctured new seed, which, in two or three years, came to full size and maturity, and were proof to the prevailing disease.

A writer who appears to molerstand this subject, (the editor of the Buffilo Commercial Advertiser,) satys, "The latter opinion in Scuthand, Germany, Sweden and Russia, is, that, by long propagation, without recurring to the natural seed of the plant, it has lo:t a portion of its vital power, and hence is extremely prone to blight, to rust and to rot."

Now, though there are several rarieties, and good ones, which produce no balls or blos.oms, it is not thence pusitively to be inferred that they have lost none of their vital power. The old age of a stock comes on gradually, and these, it is probable, though they liave not reached the stage of visible decay, are not far from it. Neither does the fact that some new rarieties have suffered more than some old oncs, militate very strongly argainst my position, unless it can be proved that the said new rarieties, were not only from seed of a new stock, but seed of a healthy and perfect quality. It does appear that entirely new varieties, and seed obtained from new countrics have, on the whole, suffered much less than old ones.

It is self-erident that, as sickly and weakly parents are seldom blessed with strong and healthy offspring, so neither will imperfect seed produce perfect, thriving plants. I therefore recommend, where seed is suspected, to come to the root of the evil, as did the agriculturists of Ireland, in the 
matter of the apple potatoc, and as the Nova Scotians do by rejecting it altogether. The potatoes planted should be of good size, and not cut into small pieces. You may as well expect a vigorous blade of corn from a diminutive, slirivelled grain, as a strong plant from a small potatoe. There never was a more fital error than the common one that "any pota toes are good enough for planting:"

It is confidently asserted by many writers, and I believe it to be true from ly own experience and observation, that the weakness of the seed is usually caused by orer-ripeness; that is, by coming to full maturity before being taken from the gromul. The best potatoe growers dig their seed potatoes before they have quite completel their growth. They are full of sap, and remain so. From the fact that they are too waxy for the talle, they are the fitter for seed. Seed potatoes should not be of a mealy quality, nor should they be stored so that they will heat, or be kept out of the ground long after they are cut for planting.

It does not follow that all potatoes of what are called new rarieties are necessarily equally new. Some of them may have gone through more generations than others. I have been forcibly struck with the truth, as it secms to me, that most varietics now in rogue are actually dying slowly of old age, the principles of decay being more or less quickened by unfarorable seasons or unskillful management. The chenango, for example, has been among the longest cultivated by farmers, and has been, perhaps, the most affected by disease. English whites and reds have not suffered so much, being of a hardier constitution; but they, too, have, for years, been showing symptoms of decay. Perhaps the wisest course, universally, would be to obtain new varieties from the seed, or to resort to the wild South American original. 


\section{CHA P'T E R İ.}

Sonce Account of the Appearance of the Disease in Different parts of the World, and the Means taken to arrest its Progress.

Tine British Government late issued a commission to proceed to Ireland, for the purpose of examining into the causes of the disease. The commission consists of Professors Kane, Lindley and Playfair. Their first report, directed merely towards improper methots of storing the crop, has been published by the Irish goverment, and distributed by means of the constabulary, through the whole country.

In Ireland the official inquiry is essentially aided by the important evidence collected by various diligent inquirers, especially by the Royal Irish Agrieultural Improvement Society, a most zealons and useful association, and the officers of the Royal Dublin Society. In England the Rev. M. J. Berkeley and Mr. Edward Jolley, are occupied with a minute investigation of the sulject for the IIorticultural Society, in the mycological and chemical points of view; and in Scotland the Agricultural Chemistry Asseciation have put forth a circular inviting the public to subscrile five lundred pounds for the expense of an entomologico, butanice, chemico practical examination of the matter.

The following is the report above alluded to: 
Board Room, Royal Dublin Society, 24th October, 1845.

Mr Lond, - We, the undersigned Commissioners, appointed by IIer Majesty's Govermment to report to your Excellency on the state of disease in the potatoe crop, and on the means of its prevention, have the homor to inform your Excellency that we are pursuing our inquiries with unremitting attention.

We are fully sensible of the important and diffeult nature of the inquiry, and therefore are unwilling to offer, at the present moment, any final recommendations, as we are still receiving evidence, and awaiting the results of various experiments now in progress. But at the same time we ought to state to your Excellency that we have reason to hope that the progress of the disease may be retarded by the application of simple means, which we trust may appear wortliy of adoption, until we are enabled to offer further recommendations.

In the present communication we avoid entering into any account of the origin or nature of the disease; but we would particularly direct attention to the ascertained facts, that moisture hastens its progress, and that it is capable of being communicated to healthy potatoes when they are in contact with such as are alrearly tainted. A knowledge of these ficts, determined, as they have been, by experiment, and argreeing with the scientific information obtained as to the causes and nature of the disease, lead us to propose the adoption of the fullowing plan for diminishing the evils arising from the destructive malady:

In the event of a continuance of dry weather, and in soils tolerably dry, we recommend that the potatoes should be allowed, for the present, to remain in the land; but if wet weather intervene, or if the soil be naturally wet, we consider that they should be removed from the ground without delay. 
When the potatoes are dug out of the ground, we are decidedly of opinion that they should not be pitted in the usual way, as the circumstances under which potatoes are placed in ordinary pits are precisely those which tend to hasten their decay.

We recommend that potatoes when dug should be spread over the field, and not collected into heaps, and if the weather continue dry and free from frost that they should be allowed to lie upon the field for a period of time not exceeding three days.

The potatoes, after being thus dried and improved in their nower of resisting disease by the means proposed, should then be sorted, by carefully scparating those which show any tendency to decay. Those potatoes which appear to be sound should then be placed about two inches apart in a layer, and over each layer of potatoes should be placed a layer of turf ashes, or dry turf mould, or dry sand, or burned clay, to the depth of a few inches. Thus will be formed a bed of potatoes, each potatoe being completely separated from the other by a dry absorptive material; upon this bed, another layer of potatoes should be spread in like manner, and be also covered with the dry materials employed; as many as four layers may thus be placed one abore the other, and when the heap is completed, it should be covered with dry clay, straw, heath, or any other material adapted to protect it from rain.

In the event of the weather becoming wet these recommendations are not applicable. In that case we would advise that the potatoes be packed in small heaps, witlı either straw or heath interposed, and well covered; in such a situation they would become as well dried as seems practicable under the circumstanees. Where outbuildings exist, it would be advisable that this mode of temporary packing should be carried on in those places. If there be no outhouses the heaps may 
be left in the open field. We, however, particularly recommend that potatoes should not be removed into inhabited rooms.

With regard to the treatment of potatoes alrearly attacked with the discase, we have to state that in this early stage of our investigation we do not fiel justitied in proposing to your Excellency any mode of positive treatment, - this subject we reserve for a future report; but we may remark that exposure to light and dryness, in all cases, retards the progress of alterations, such as the discase in question, and we therefore sugrgest that all such potatues should, as far as possible, be so treated.

We do not mean to represent that these recommendations, if carried into effect, will prevent the occurrence of disease in potatoes, but we feel assured that the decay will extend less rapidly and less extensively under these circumstances than if the potatoes, when taken from the ground, be at once pitted in the usual mamer. Neither do we offer these suggestions to your Excellency as a final means of securing the crop, but merely as a method of retarding the progress of an enemy whose history and habits are yet but imperfectly known, whilst we endeavor to ascertain the means of more completely counteracting its injurious effects, if any such can be discovered.

All which we submit to your Excellency's consideration, and remain your Exeellency's obedient and faithful servants,

Robelit Kane,

JoHN LINDLEY,

Lyon Playfair.

In France, the French Academy of Arts and Sciences deputed M. Charles Morren, of Liege, to examine into the cause of the potatoe rot. Mr. Morren is a foreigner, and his selection by the French, for this inquiry, is a sufficient guar- 
antec for his talents and ability. This gentleman states the result of his investigation to be, that the rot is eaused by a fungus, the sprores or seeds of which exist in vast quantities in the atmosphere, and this opinion has been generally received as true by the best informed circles in Europe. But the letter is a document so important to the present question, as conveying the prevailing opinions that are entertained on this sulject in Europe, that we quote it below.

Mr. Morren, after stating that the evil has prevailed in Belgium for sereral years, though to a far less alarming. degree than at present, proceeds:

"The real cause of the evil is a fungus, or sort of mush-. room, which the learned will classify under the genus botrydis, but which agriculturists, without further specification, will call a spot, or blemish, or blotehes. This mushroom is of extreme tenuity, but it breeds amazingly, and reproduces itself by thousands. Its stems are formed of little, straight, hollow threacls, which bear on their summits onc or more branches, always divided into two, and at the end of these branches reproductive bodies are found, which have the form of eggs, but which are scarcely the hundredth part of a millimetre in size. It will be said that this is a very small body to do so much mischief; but $I$ answer that the $i$ tch is not a disease the less to be feared because the acare which produces it can only be seen by the aid of the microscope.

After the formation of the yellow spot, and the developement of the botrydis on the leaf of the potatoe, the stalk receives the deleterious influence. Here and there its epidermis turns brown, blackens, and, following with the microscope the phases of the evil, you perceive that it is by the rind that the stalk is attacked. The morbid agent carries its action from the rind on the epidermis, and though this last does not always disclose mushrooms, it is not the less for that struck with death. 
The infection soon descends into the tubercle itself. If the disease follows its course, the tubercle mortifies forthwith. A potatoe is not a root, but a branch, whence it follows that a tubercle contains a marrow, which is the eatable part to be preferred, and a separate rind; between the marrow and the rind there is a zone of ressels, which represent wood. This construction is apparent to any one who chooses to cut a thin slice of potatoe, and place it between his eye and the day light. The infection attacks that part which receives the sap on its descent.

By following the progress of the evil upon a great number of tainted tubercles, I have been able to see how the evil, by one continuous progress, at length reaches the heart itself of the potatoe, and corrupts the regetable entirely. The skin of the diseased potatoe comes off easily; the flesh cracks under the knife: a flatulent liquid drips from the potatoe; a musty, and presently an animal smell, analogous to the smell of mushrooms recently cut, manifests itself, and occasions considerable nausea.

The evil being traced to its source, the cultivator must direct all his attention to the destruction of the fungus, or mushroom, for it is unfortunately but too true that all the parasites of this genus once introduced into a country, remain there and propagate. This year the epidemic has been general ; the germ exists every where: millions upon millions of propagules, if their numbers are not diminished this year, will next year attack the plants, and then it will be more difficult to eradicate the scourge.

It is essential to adopt the following precaution:

When the leaves are decidedly spoilt, cut down the vines forthwith, and burn them on the spot, instead of taking them away.

When certain varieties or certain localities are free from the scourge at the time of the harvest, it is always prudent to 
burn the leaves, for a field may appear secure from the botrydis, when it is not so; several leaves are attacked; these leaves throw the propagule on to the tubercles, which, if preserved for the purposes of reproduction, will spread the plague the following year.

If the potatoes themselves are attacked, it is essential to separate as speedily as may be, the potatues that are tainted from those that are not. Turn the sound ones over to account as soon as possible, for they are not noxious so long as the rind does not become yellow. The diseased ones should be burnt.

As it is probable that the tubercles preserved for seed will be infected with the spawn of the mushroom, it would be advisable for cultivators who can, to procure tubercles for reproduction from places where the present scourge is unknown.

In case of using for reproduction the tubercles of crops wisited by the plague this year, it will be necessary to submit them, previous to planting, to the agency of lime, as it is practised with wheat and all plants that are liable to invasion by parasitical bodies. The process onght to be by the immersion of the tubercles in lime water. Fifty pounds of lime, a quarter of a pound of sulphate of copper, and six pounds of marine salt, for twenty-five quarts of water, constitute a preparation, the utility of which, in the destruction of parasite regetation, has been experienced by a great number of well-informed cultivators.

In the plantations of the spring of 1846 , it is essential to plant potatoes in fields as far as possible removed from those actually infected this year, to avoil the danger from the retention in the soil of the spawn of the fungus.

The use of lime and manure salt, with a slight mixture of sulphate of copper, is, as I have already said, of acknowledged efficacy in the destruction of parasite germs. Conse- 
quently, to powder over with such a mixture, a soil in which diseased potatoes have grown, is a good operation for destroying in that land the germs of the scourge. The operation ought to be recommended everywhere.

The storing of potatoes from fields that have this year been attacked by the scourge, in cellars, caves, \&c., will certainly be to deposit the spawn of the mushroom in those very places. They should, therefore, before receiving the potatoes, be thoroughly cleansed, and scoured with lime, or ground charcoal scattered over the bottom, (and on the potatoes as they are stored,) which will conclude the series of operations, the most rational and the most certain for destroying, if possible, the evil at its root.

\section{H. Morren,}

ITember of the Royal Academy of Sciences.

Liege, August 14, 1845."

The Journal of the Royal Agricultural Society, sixth volume, contains an article on "The prevention of curl and dry rot in potatoes," by H. S. Thompson, which is valuable and interesting as it contains the result of extensive observation and experiments on the subject, for the, last five years. The editor of the New England Farmer thinks that "the disease therein described is analogous, if not identical with the one so prevalent in many sections of our own country," and, he adds, "it may vary in its effects in different soils, seasons, or climates." Mr. Thompson commences his article by first mentioning the results to which he has been led, which are:

"That curl and dry rot are caused by leaving the potatoes intended for seed in the ground until ripe, and that, on the other hand, these diseases may be prevented by taking up the seed potatoes whilst the tubers are unripe and the tops still green."

1840. "Having had my attention strongly drawn to the 
failure in the potatoe crop," says Mr. Thompson, "I paid more than ordinary attention to the selection of seed, and in 18.10 planterl sixteen acres with potatoes, making choice of two kinds of round red varieties, both of them new to my land. The gentleman from whom I obtained them, having two farms, one of stiff, the other of light land, - had changed his sets regularly from one to the other. I planted them on a sandy loam, which was in a high state of cultivation, and my reason for planting it with potatoes was solely because I was aware if sown with corn it would be so lodged as to be nearly worthless. They were planted in the last week in April. I naturally expected a heavy crop, but was much disappointed, as symptoms of curl soon appeared. This increased, and though few of the plants perished, nearly the whole were unhealthy. I was so much surprised at the appearance of curl that $I$ watched and examined the plants at several periods of their growth, taking up roots here and there wherever I observed one either better or worse than its neighbors. The appearance of all those affected was nearly the same. The set, as long as the weather was dry, crumbled and perished, - the disease seeming to proceed from certain spots or pits as centres, and gradually destroying the whole set. The cut sets were the worst, and the decay always commenced from the cut side of the set, but the whole ones also suffered.

As soon as the weather became wet, these appearances changed, and the diseased portion of the set resembled a sponge, which after a short time became black and offensive. The effect on the plant was well marked. Wherever the disease had made a decided impression on the set, the stalks of the plant were marked with brown streaks and patches, and evidently showed that the juices which they were conducting from the set were vitiated and noxious. The part of the stalk to which I directed my attention was that under- 
ground, in which it was easy to trace the progress of the disease, from their being white and nearly transparent. Wherever the stalk was curled, I found the sets diseased. In :some eases the disease carried the day, and the set reaching . In advanced stage of decomposition, and the stalks below : ground becoming quite brown, the tops died away. In a subsequent season (1844) most of the sets attacked perisherl; but on this occasion a great majority of the plants threw out strong roots, and finding an abundant supply of food, maintained a constant struggle with the disease, and eventually yielded a good half crop.

The experience of this season convinced me that curl, dry rot and wet rot, are one and the same complaint; that curl is a mild attack of the disease, which, when violent, destroys the set before it can germinate; and that it assumes the form of dry or wet rot according to the degree of moisture of the soil or season. I have repeatedly seen potatoes affected with dry rot, in a few days assume appearances by which wet rot is usually described; and this change was evidently attributable to heavy rains which had fallen in the interval.

1841. As I still considered the red potatoes above-menrioned to be good kinds, and that the occurrence of curl was accidental, I determined to give one of them another trial; and accordingly, I planted about an acre and a half with sets from the crop of 1840 , which had suffered so much from curl. They were planted as late as the 8 th of Jume, the weather dry and unfavorable; yet in spite of these disadvantages they came up well, grew luxuriantly, and produced an excellent crop. Side by side with these potatoes two other kinds were grown; one a black kidney, a very superior potatoe for the table, the other a cattle potatoe. These were bought sets, nor do I know how they had been previously treated. Both, however, were failing crops. The experience of this year was valuable, running directly counter to what has been so 
frequently asserted by the authorities, namely, "that curl is sure to inerease, and that curled sets are to be aroided litie the plague." The explanation of the rule and of this exception to it, appears to me to be as follows:

Curled potatoes ripen early, some weeks before the healthy plants, and consequently are almost always too ripe, when taken up, to make good sets, and if so used the disease will rapidly increase each successive season.

In this instance, however, the infected potatoes were taken up before they were ripe, and proved tc be as good sets as could be used. The potatoes above-mentioned were taken up the second week in Norember, 1841. Having been planted so late the round reds were not ripe; the black lidneys, a much earlier variety, were.

1842. The same potatoes were used for seed this year. The unripe reds produced un excellent crop, without, so far as I am aware, a single failing plant. The ripe black kidneys were again a failing crop. ' In the middle of May I planted, with these black kidneys, a small piece of old grass land, as a preparation for forest trees. This plot of ground had been from time immenorial flowed over by the waste water from an old and ill-constructed farm yard, immediately adjoining, and was therefore as rich as could well be imagined. The potatoes had immense tops, but rery small tubers; and, when boiled, the favorite black kidneys seemed quite to have changed their character. Instead of the fine mealiness for which they are remarkable, they now bore much resemblance to a piece of. yellow soap. They also continued growing till the frost and snow made it dangerous to leave them any longer in the ground, and they were taken up still thoroughly unripe. The round reds, grown on oldgoing land, were taken up ordinarily ripe, and were mealy and good.

1843. These two kinds were again used for seed, and 
the white reds had numerous failures, but the unripe black kidneys were as even and vigorous a crop as could be wished. I had not yet learnt to attribute the failure to its right cause, and was accordingly much puzzled to account for the curl among the round reds, which had thriven so well the two previous seasons. In consequence of the heavy fall of snow in October, they were taken up earlier than was intended, and the red potatoes were not ripe, but the black kidneys, (a capital crop) were.

1844. It was during the spring of 1844 , that I became convinced that the maturity of the potatoe intended for seed materially affected the vigor of the future plant; and the crop of this year furnished me with some facts strongly corroborative of this opinion. The ripe black kidneys again failed to a great extent; not less, I think, than half the sets perished without regetating, or only showed puny curled tops, and died without forming tubers larger than peas. 'The unripe reds were planted in a particularly unfavorable place, namely, an old lane which had been just added to an adjoining field, and was so hard and dry that parts of it had to be broken up with pirkaxes. In consequence of the loug drought the planting was delayed for several weeks in hopes of rain, but as none cane they were put into the ground as dry as dust and planted without manure; no rain, with the exception of a light shower, fell till the potatoes were up. Still, in the whole of the piece, rather more than an acre, I could not discover that a single plant had failed, and the braird was universally strong and healthy. It will be well to present their results in a tabular form. I shall assume that the red potatoes bought in 1840, and the black kidneys in 1841, Inad been taken up ripe; and their mealiness will justify such an assumption, as unripe potatoes are always watery, and unfit for the table. 
Round ReDs.

\begin{tabular}{|c|c|c|c|}
\hline Tear. & Seed taken up. & Quality of crop. & Quantity of crop. \\
\hline $\begin{array}{l}1840 \\
1841 \\
1842 \\
1843 \\
1844\end{array}$ & $\begin{array}{l}\text { Ripe, supposed } \\
\text { Unripe } \\
\text { Unripe } \\
\text { Ripe } \\
\text { Unripe }\end{array}$ & $\begin{array}{l}\text { Curled } \\
\text { No Curl } \\
\text { No Curl } \\
\text { Curled } \\
\text { No Curl }\end{array}$ & $\begin{array}{l}\text { Failing crop. } \\
\text { Good crop. } \\
\text { Good crop } \\
\text { Indifferent crop } \\
\text { Good crop }\end{array}$ \\
\hline \multicolumn{4}{|c|}{ Black Kidneys. } \\
\hline $\begin{array}{l}1841 \\
1842 \\
1843 \\
1844\end{array}$ & $\begin{array}{l}\text { Ripe, supposed } \\
\text { Ripe } \\
\text { Unripe } \\
\text { Ripe }\end{array}$ & $\begin{array}{l}\text { Curled } \\
\text { Curled } \\
\text { No Curl } \\
\text { Much curled }\end{array}$ & $\begin{array}{l}\text { Failing crop } \\
\text { Light crop } \\
\text { Capital crop } \\
\text { Very bad crop }\end{array}$ \\
\hline
\end{tabular}

Had the above results been obtained by experience contrived for the purpose, they could not have borne more directly on the point in question, as we find in the wet summer of 1843 , and the extraordinary drought of 1844 , as well as in the average seasons of 1841 and 1842, it accidentally happened that part of my potatoe crop was grown from ripe, and another part from unripe sets, and in every ease with success from the one, and failure from the other; thus showing that the seasons could not be blamed as the cause of curl. To make these instances still more conclusive, it also happened that each of the two very different kinds of potatoes named were alternately affected by or free from curl; thus showing that it was not a peculiarity belonging to a particular lind of potatoe.

Thus far I have detailed my orn experience only; but when it first occurred to me that over-ripening of the set was the cause of the curl, I naturally became anxious to compare the experience of others with my own, and make many inquiries on the sulbject from other potatoe growers. The information thus received still more strongly confirmed me in my previous opinion, and I select one or two of the cases 
which appear to me most in point. The first gives the result of two opposite methods of treating potatoes intended for seed as practised by two intelligent farmers.

The first farmer has planted the same kind of ash-top kidney for more than ten years. The first year or two he took up those intended for seed at the same time as those intended for consumption: but found that they grew so much during the winter that they were obliged to be sprouted twice, which weakened the set so much as to injure the crop. IIe then tried the effect of leaving them longer in the ground - sometimes as much as three months after the plant was ripe. This produced the desired effect of preventing the growth during winter; but after some years' continuance he found the germinating power so much injured that they were a month or more later in coming up than those of his neighbors, treated in the ordinary way. In fact, he could scarcely get them to grow at all, and was forced to change his plan.

The second furmer has grown ash-top kidneys for some years, and finds them better and earlier than when he first got them. Is in the habit of planting those he intends for sets after taking up his crop of cabbages, which is at the end of June or begiming of July. IIe also takes them up before they are ripe; never finds them fail; they grow earlier in spring than potatoes not so treated, and make stronger and healthier plants.

The contrast between these two instances is very complete. Two men, living not above two luundred yards from one another, and whose gardens are almost precisely similar, grow the same kind of potatoe in the same seasons. The potatoes of the last named being taken up unripe, improve both in vigor and carly maturity, while the first, which are left in the ground till over-ripe, will scarcely grow at all.

Another case. A farmer in Tawden, near Scarborough, (which some years ago supplied large quantities of potatoes 
for seed,) has been a potatoe grower for thirty years, used formerly to send five or six hundred bushels of Tawilon kidneys annually to Selby, where they were used for seed, and the produce sent to London. IIe used to grow two hundred bushels to the acre, but now considers fifty bushels a good crop; has failed so repeatedly the last five years in growing a crop, that this year, 1844 , he has none, and believes there is but one man in the township who continues to grow the kidneys.

I will now state the chemical facts which appear to me to confirm and explain the above-mentioned results of practice. It is notorious to potatoe growers that a marked change takes place in the quality of the tuber when the stem and leaves wither, and that potatoes taken up when the plant is still growing, are watery, though a portion of the same plot, if of a good sort, and in suitable soil, taken up a few weeks later, will be found light and mealy. This is probably owing to the deposition of starch in the tuber by the descent of the sap, when the growth of the plant has ceased, and is apparently analogous to the very similar process described by Liebig as taking place in all perennial plants.

"All the carbonic acid which the plants," remarks Liebig, speaking of peremial only, "now absorb, is employed for the production of nutritive matter for the following year. Instead of woody fibre, starch is formed, and is diffused through every part of the plant by the autumnal sap." To remove every doubt on the subject, however, I took up portions of two kinds of potatoes, growing in very different situations, and a ripe and unripe sample of each, to an analyzing chemist, merely numbering the samples, and requesting to know the per centage of starch in each. The result was as follows: 
Water. Starch. Dry fibre.

No. 1, Black Kidneys, Unripe, $68.7 \quad 17.7 \quad 13.5$

No. 2, do. do. $\quad$ Ripe, $\quad 72.0 \quad 17.9 \quad 10.0$

No. 3, Round Reds, Unripe, $69.8 \quad 15.1 \quad 15.0$

No. 4, do. do. Ripe, $73.8 \quad 17.9 \quad 8.2$

The proportion of water in the unripe samples here seems to be four per cent. less than in the ripe samples, having been taken up some weeks earlier, and kept out of the ground until the others were considered ripe enough. Neglecting the water as unconnected with the present inquiry, we find that the proportion of starch to the other solid matters is as $177: 135$ in the umripe kidneys, but as $179: 100$ in the ripe; or reducing both to a common measure, he have :

Starch: other solid matters : : 131: 100 in the unripe kidneys. : : $179: 100$ in the ripe do.

In the round reds reducing as before to a common measure :

Starch: other solid matters : : $100-100$ in the unripe reds. $216-100$ in the ripe do.

In each case it thus appears that the proportion of starch to the other solid matters had increased considerably in the interval which had elapsed between taking up the ripe and umripe parcels. The remark will probably be made here, that though an increase of starch has undoubtedly taken place, yet the quantity present was considerable before, why then should an addition to it injure the germinating power of the set? To answer this question it is necessary to state briefly the doctrine propounded by the most eminent vegetable physiologists of the present day, who aflirm that during the act of commencing germination a substance called "diastase," is generated from the nitrogenous substances contained in 
the germinating seed, which diastase assists in the conversion of starch into the gum, sugar, \&e., which are required for the nourishment of the young shoot. The potatoe contains a very small per centage of nitrogenous matter. I would, therefore, venture the sugrestion that the great addition made in the process of ripening, to the already large stock of starch contained in the tuber, may be more than can be converted into the gum, sugar, \&.e., lyy the small cquantity of diastase generated in the germinating potatoe. If this be the case, then it would follow that the diastase being mixed with too large a proportion of starch (like learen mixed with too large a proportion of dough) only does its work imperfectly, and the result is a weakly shoot, whilst a portion of the starch, failing to receive the ritalizing infuence of the diastase, undergoes the natural course of decay, and produces the symptoms peculiar to dry-rot, wet-rot, or curl. This supposition is, of course, pure theory, and must not be confounded with the facts on which it is based. To make it quite clear where the one ends and the other begins, I will very briefly recapitulate. Facts have been brought forward to prove that ripe sets are subject to curl, and vice versu, also that a large addition is made to the cuantity of starch in the potatoe in the process of ripening. Direct experiment also proves that "diastase" is required for the germination of seeds, which diastase can only be formed from some substance containing nitrogen ; potatoes contain a very small proportion of such substances, and therefore can have but very little diastase. Here our facts end, but from these premises I would hazard the decluction that if we allow our seed potatoes to rinen, they acquire more starch than can be made available to the growing shoot; which excess naturally decays, and then infects and injures, or even destroys, the plant with which it is connected. A similar effect is produced in the human sulject when more food is taken into the stomach than the gastric 
juice is able properly to digest. The imperfectly converted aliment produces various kinds of inconrenience, and, if persevered in, derangement of the whole system, though the food itself in moderation may be perfeetly wholesome.

It would be doing injustice to the theory before stated, if it were sent forth to the public without a brief notice of some of the oljections which at once occur to those conversant with the subject. The first that I shall allude to is, that the management of seed potatoss during winter, the mode of planting, and more especially the nature of the season after planting, exercise a very decided influence in modifying or increasing the potatoe failure; which, at first sight, seems liardly reconcilable with the supposition that such failure is dependent on the degree of maturity of the seed potatoes when harvestecl. I at once admit that if seed potatoes are kept in too large a heap and allowed to ferment, or if lept so warm as to induce excessire growth during winter, or in any other way are so treated as to weaken their vitality, the sets will, many of them, fail, and others make weak and unhealthy shoots, very much resembling, and possibly identical with, curl. It must be borne in mind, however, that though I consider over-ripening of the seed to be the ordinary cause of eurl, I by no means assert that it is the only one. I an well aware that deficient management will, especially if followed by long drought, produce failing crops, and whether such failure be due to enrl or not, I can offer no opinion; but the great puzzle to potatoe growers has been that, with the most careful management, failures continually oceur, and these failures may, I think, be traced to ripe sets. That the influence of season is great I should be the last man to deny, as in two instances where my potatoe crops were affected with curl, (distinctly traceable to having used ripe sets, ) they contimed to get worse so long as the drought lasted, but on the occurrence of heavy rains 
they improved very much; and this is quite in keeping with my theory, as when once the plant has a stem and leaves whereby to elahorate nourishment from the atmosphere, and roots which purvey from below, a large supply of moisture will give it such an abundant flow of sap that the vitiated juices of the decaying set will both be very much diluted and the plant will derive sufficient vigor from external sources to outgrow a slight ailment; whereas in a dronghty season, the plant is much more dependent on the set, and this at such a time furnishes the poison in a concentrated form.

The next objection I shall notice is, that one of the best ways of getting rid of curl hitherto known, is to grow the potatoes intended for seed on a piece of old meadow or other land that has been long uncropped. This is easy of explanation. Fresh land contains a supply of food which has been accumulating for jears, and accordingly produces a more luxuriant growth and later maturity. Every one must have remarked that in a dry season plants of all kinds are less fully developed, but ripen earlier. This is doubtless owing to the less liberal supply of nourishment which they receive; for even where the land is abundantly manured, plants cannot avail themselves of it without moisture. When a plant has attained a certain stage of growth, even though considerably below its ordinary developement, should its supply of food be stinted, cither in consequence of drought, or of a searcity of the necessary elements in the soil, it will at once proceed to form and mature its seed. This is readily observable in the case of weeds. The same species of grass which is common in our meadows will be frequently found growing by a roadside, or even on a gravel walk, and in dry weather will flower and hear seed, though so stunted and dwarfish as scarcely to be recognizable. This will occur considerably earlier in the season than the time of ripening of the same species of grass in an ordinary meadow, and again 
the meadow-grown plant will ripen far before another of the same species grown by a ditch side or in other moist, rich soil, and this last will as much exceed the meadow plant in size and lnxurianee as the one in the meadow did the one in the gravel walls. The Poa anmun is a species of grass which may frequently be find in all the three situations abore named. That potatoes are not exempt from this law of nature I have lial aluandant proof. On the occasion previously mentioned, where I planted potatoes on a piece of rich old turf, soaked for years with the drainage of a firm-yard, they never did ripen, but grew on through the whole antumn, and were as green and vigorons in November as they had been in July. At last a leavy fall of snow came, with a severe frost, and in forty-eight hours they were as black as if they had been lumt, but the tubers were still thoroughly unripe, and were the very worst on the table and made the best sets that I have ever possessed. In 1844 I had also a strong instance. In reclaiming an old lane some parts had to be lowered and some hollows to be filled up, and both being planted with potatoes at the same time, those planted where the old hollows had been, and which now had a considerable depth of fresh soil, grew considerably taller and ripened some weeks later than those on the ridges whence the soil had been taken; though even in these places considerable pains were talien to retain as much of the surface soil as possible; and as the ridges and depressions ran parallel to each other for forty or fifty yards together, the markerl difference in the time of ripening caught the eye at once. I have also frequently observed that potatoes planted near hedgerow trees (especially ash) ripen earlier than the rest of the fiekl. It thus appears, as well by the analogy of other plants as by direct observation of the potatoe itself, that a deficiency of nutriment produces early maturity, and vice versa. Fresh soil, it will at once be admitted, contains an 
extra supply of food; potatoes, therefore, grown on such soil, will be in a growing state when those on old-going land will be quite ripe, and if harvested together the former will be unripe and make good sets. It is very probable, however, the more abundant supply of all the elements of nutrition to be found in fresh soil may have a considerable effect, and concur with the under-ripening of the seed in producing a healthy and vigorous plant. 


\section{CHAPTER II.}

\section{A View of the different Theories entertained on the Potatoe Plague.}

Tre article from Mr. Thompson, which forms a large part of the preceding chapter, has been given almost entirely as it was originally published, because it contains, I believe, the most rational theory that has yet been promulgated on the nature, cause, and cure of the Potatoe Plague. It is true that his argument does not extend so far as to cover the present appearances which the plague has assumed, but it leads us to expect results precisely similar to those which are now recognized with reference to it, and may be regarded as prophetic, if, indeed, the view he has taken, be not assigned to the true cause, namely, a discorcry of the causes producing the muludy. A remarkable feature in the history of potatoe cultivation is, that it has been free from a variety of diseases, though, as before remarked, it has been subject to disease from a very early period of its existence. The Curl and the Taint, which last is considered a modification of the other, are the only diseases of which any mention is made by writers on the subject, from its furst introduction as a field crop to the present time. Now Mr. Thompson's article, though it is professedly on the curl in potatoes, looks forward to a developement of this disease, assuming a malignant type, which would ultimate, as he has predicted, and exactly as we have 
experienced in the present crisis of the potatoe crop. If his view be correct, and we believe it is, we need look no further for the cause of the discase, for it is evident to all, that the great difficulty in finding a remedy to stay the progress of this fearful calamity has been, that its true nature was not understood; but being understood, a remedy, simple, and universal is at hand. Before entering upon this part of the discussion, however, it will be necessary to give a view of other theories and opinions that are entertained, together with the experience and statements of cultivators in different parts of the country.

A writer of considerable eminence in the field of Agricultural literature, says:

"The first symptom of degeneracy of the plant in ScotIand, appeared about 1780, when the distemper called the curl was first noticed in the crop; but it then occurred so rarely that very little notice was taken of it; the evil gradually and extensively increased, when, about the year 1784 or 1785, the whole crops of Lothian were seriously affected by it. A remedy, however, was accidentally discovered, by changing the seed from the high country; and this was and has been the only remedy for the disease of the curl to the present day. At this early period the seed procured from a high country had to be changed every three or four years, but it was found, as the cultivation of the plant increased, so did the disease, and eventually the whole seed had to be changed yearly, as it was found a new disease appeared in the fields - the seed only partially germinated - great blanks or failures took place - and many farmers lost almost their whole crops. This disease in the seed was called the wet and dry rot; and, in many instances, seed from all situations, high and low, has now also failed. These two kinds of disease which destroy germination have been variously accounted for. Some ascribe the cause to maggots and flies, 
who feed upon and destroy the seed plants; but this is a consequence, and not a cause, for maggots and flies are only to be found on diseased or putrid regetables; they riot and banquet on putrefaction; it is their natural food, and there they are only to be found. Plant, then, a sound potatoe in a good soil, and, properly treated, it will find its way to the surface, and produce a good crop in defiance of maggots and flies.

The seeds of disease, then, must be in the constitution of the plant.

In examining a diseased potatoe, which has blind eyes, and will not germinate, it is plain that there is canker on the skin, and plague spots all over it. This, if planted, will certainly be attacked by the magrots and flies; but the plant is in a state of decay or putrefaction - in fact a ceput mortum - and it properly belongs to the flies and maggots by right of inheritance. The great object to be attained, then, is to plant sound seed, and the maggots and flies will not relish it. It is generally allowed, and the idea has been long entertained, that it is quite impossible to raise seed potatoes in low situations or in a high temperature, without being affected with the curl; but at an altiturle of four hundred feet it entirely disappears. In this there appears to be a very remarkable peculiarity in the nature and constitution of the plant; but in looking to its origin, general history, cultivation and general management in this country, - its success and failure, - I have been led to a far different conclusion. Indeed, from what I have already stated, it must clearly appear to every one, that there can be only one cause for the failure of the potatoe plant, to wit, over-cultivation.

The first practical experience of fuilure which I met with on my own farm, struck me most forcibly. In the year 1837, I had a small quantity of potatoes for seed, which I had receired from high grounds. I thought them very fine, and 
having selected the best for seed, I manured the ground heavily in the drill, with the richest and best dung on the farm, in order to late as many as possible for planting the suceeding year. The extent of the ground was about an acre, and I certainly obtained an excellent crop. But as I never plinted a whole field in the same way without some variation by way of experiment, a few drills of similar seed were placed next to them, very moderately manured. At the time of taking up the crop, the plants were still green in the tops. The few drills already mentioned were pitted on the end of a pit not meant for seed, and the produce of the acre was pitted by themselves. Next season $X$ planted the greater part of the produce of the acre in the usual way, and lost one thind of the crop. I also planted the produce of the few drills in the ordinary way, and had a little curl, but not a single blank.

$M y$ view is that a heavy or over-grown crop of potatoes, in any soil or situation, will always yield bad seed potatoes; and that orer-cultivation is the sole or chief cause of the degeneracy of the plant; and all my experience completely confirms me in this position.

I come now, says this writer, to the cure, or remedy of the disease, or the best means of procuring and raising good seed. I would recommend to select the best varieties, and raise from the apple; but, in the mean time, to have the best and soundest seed for present planting, - always, of course, aroiding the produce of a great crop, grown in any situation or soil. The land intended for seed should be ploughed deep in the autumn. The drills to be thirty inches wide, and manured moderately, with a mixture of earth, and if earth has not been previously mixed with the manure, a little may be drawn into the drills abore the manure, and before planting the seed. 'The ground intended for seed should be planted with whole potatoes, and about fourteen inches apart, 
or the potatoe cut into two pieces, and planted at ten inches, (loth may be tried;) the plants to be placed near the surface, and never highly earthed up by the plough, as it is natural for the tubers of the plant to run upwards, and the more of them that may be exposed to the sun and aid in ripening, will make so much better seed. 'They should be taken up rather green and unripe than ofherwise, but approaching to a ripe state. They should be plincer in pits, (in an airy situation,) of about two aml a half fiet at bottom; the pits may be made of tolerable lengtle. They should have first a little earth thrown over them - say, half an inch - and then a good covering of straw, finishing with a few inches deep of earth, as it is the straw which will defend them from frost, and a few straw fumcls at a short distance is all that is necessary.

In stating the canse of the potatoe rot, a correspondent of the Maine Farmer, F. G. Puxton, states an experiment which he made in growing some potatoes in the cellar, in a dark place, and they were affected with rot, like those raised in the field. From this he infers that the disease is not caused by rust, heat, cutting the seed, de., but that the cause is in the potatoe. Some person, commenting on this, attributes the cause to lisease in the presious crop, which was not perceptible, and was transmitted to the new produce.

Sereral pamphlets on this subject have been published in Great Britain and France, the contents of which, and the riews entertained hy their compilers with regard to the causes and remedies for the malady, I shall now briefly state.

In the Comptes rendus, MI. Payen states the result of his chemical investigations. Ile finds what he calls the dry matter, that is to say, all except the water, diminished in quantity to the extent of twelve per cent. The diseased part

* Comptes rendus Iebdomadaires, \&c., Nos. 13 to 16. Paris, 1515. 
is twice as heary as the heallhy, which lie attributes to the prrsence of a parasite. The loss of starch amounts to twenty per cent. There is present an azotized matter, having tho same composition as fungi. All the chemical phenomena point to the action of such parasites, and not to spontaneous fermentation. Messrs. Girardin and Bidard, on the other hamd, deny the presence of parasites. They find no other intication of their presence than what oceurs in all cases of fermentation. They regard the disease as the result of simple fermentation, induced by the unfarorable season. They recommended perfectly rotten potatoes to be crushed in tubs, to be thoroughly washed, by which means the foul odor is removed, and then, after draining, to be pressed into cakes, which may be dried in ovens after the bread is withdrawn, and given to cattle. M. Durand attributes the disease to atmospheric causes, fitrored by local circumstances. He knew it in former years, when potatoes were grown in damp places. IIe denies the statement that thie stems were always affected before the tubers, and he states that dryness and darkness are certain safeguards for the crop. Three liundred IIectolities have been thus preserved for a month without change, and yet they had not been very carefully sorted. MI. Gerard adverts to the admitted fact that the disease attacked the potatoes between the 10th and 15th of August. He is opposed to the idea that animal or regretable parasitism is connected with it as a cause, and he ascribes the disease to the presence of a brown matter "which seems to glue the starch grains together, and to prevent their separation." IIe attributes its presence to unfavorable atmospheric causes, which caused the nutritive fluids to stagnate, and thus produced an. alteration which ended in decay.

A Mr. Spooner has publi-hecl a pamphlet which is chiefly addressed to the question of converting potatoes into starch. 
He ascribes the disease to frost, which, however, did " not act directly on the tuber; but indirectly through the leaves."

Mr. Phillips has instituted a careful investigation of all the facts connected with the disease, and has collected some useful information. IIe is unable to find fungi, and ascribes the evil to too much moisture, the effect of long continued rains, which "stimulated the plant beyond its ability, and then overpowered it. The plant formed more pendulums, (sic) and tubers, than it could support, which being left to themselves, putrefied," \&c. Near the end of this pamphlet is a statement, that if the potatoe fields had been divided by trenches into compartments, the author has no doubt that the present disease would have been warded off. Mr. Phillips does not seem to be aware that what are called lazybeds in Ireland, are made exactly upon his plan, and, unfortunately, they are very far from having proved any security against the disease. The fact, moreover, is, that the best drained land has been as much, or more attacked, than the worst.

Mr. Buckman regards fungi analogous to that which produces smut in barley, as conecrned in the evil. IIe finds their seeds, (spores) sticking abundantly to the sides of the cells, and calls the species Uredo tuberosum. IIe does not, however, regard the Uredo as the basis and origin of the evil; he looks upon it as a mere effect attributable to the peculiar state of a late season. As remedies, he adrocates a solution of chloride of lime, or chlorine gas; but he does not seem to have any personal experience of their advantage. He also mentions the following plan, adopted by Mr. Sclater, a large potatoe grower of Exeter, as effectually stopping the further ravages of the disease. Soak the tubers for an hour in a weak solution of chloride of lime. Then dry well and soak for another hour in a solution of three pounds common soda in seventy-five quarts of water. Finally, dry them well, and store them in a dry place. We are persuaded that 
these plans, which have been so much advocated, all resolve themselves into one and only one process, which is, maintaining dryness.

The official circular of the Poor Law Commissioners, contains an extract from an official paper published in the United States, on the potatoe disease in 1843 . It appears from this document that the evil was ascribed to heavy rains and early -snows.

An able writer in the Gardener's Chronicle, G. S. Mackenzie, Bart., says: "I formerly suggested that an insect had caused the disease of the potatoe. There now scems to be some reason for believing that it has been injured by various causes, and that there is more than one disease at work. While examining a number of diseased tubers, in ono (and one only) I found two small maggots luxuriating in the rotten matter. On mentioning this circumstance, I found that some other persons had observed the same thing. In many potatoes I noticed round holes and cavities connected with them, in which larvae had, no doubt, fed. But there was no appearance of disease, the wounds having dried up In many cases the substance of the potatoe had been converted into matter of a corky consistence; in the greatest number the substance was a mass of wet rottenness.

I now give the opinion of Professor Liebig, published Norember 5. He says, "The researches I have undertaken upon the sound and diseased potatoes of the present year, have disclosed to me the remarkable fact, that they contain, in the sap, a considerable quantity of vegetable casein (cheese) precipitable by acids. This constituent I did not observe in my previous researches. It would then appear that from the influence of the weather, or generally speaking, from atmospheric causes, a part of the regetable albumen which prevails in the potatoc, has become converted into vegetable casein. The great instability of this last substance is well known; 
hence the facility with which the potatoe containing it undergoes putrefaction. Any injury to health from the use of these potatoes is out of the question, and nowhere in Germany has such an effect been observed. It may be of some use to call attention to the fact that diseased potatoes may easily and at little expense, be preserved for a length of time, and afterwards employed in various ways, by cutting them into slices about one quarter of an inch thick, and immersing them in water containing two to three per cent. of sulphuric acid. After twenty-four or thirty-six hours the liquor may be drawn off, and all remains of it washed away by steeping in successive portions of fresh water. Treated in this manner the potatoes are easily dried. The pieces are white and of little weight, and can be ground to flour and baked into bread along with the flour of wheat. I think it probable that the diseased potatoes, after being sliced and kept for some time in contact with weak sulphuric acid, so as to be penetrated by the acid, may be preserved in that state in pits.

An advocate of the theory that the disease is caused by fungus, gives the following statement:- "That this disease is occasioned by a fungus in the leaf, I have no doubt, and such $\mathrm{I}$ believe is the public opinion in general. I am equally well assured that the gangrene or mortification is a mere consequence of the fungus. If a certain predisposition in the potatoe plant, occasioned by an advanced state of the elements themselves, were alone necessary to give unbounded scope to this fungus, how, I would ask, has it happened, that this strange condition of atmosphere lias never occurred before, since the introduction of the potatoe from South America - now, I believe, nearly two hundred years? Or, shall it be said that the disease is indeed new to Europe? On looking over the weather registries for the month of August, I find that S. W., W., and N. W. winds prevailed through 
the whole month; and even extended into September, and this is, I should conceive, an extraordinary direction in regard to their continuity. Everybody has seen, according to the old phrase, "motes dancing in the sumbeams." Now, as to the sporules of various fungi, why may it not be possible for them to possess so little specific gravity as to be lighter than their own volume of air - to ascend thereby in common with mists - to be incorporated with clouds - to traverse thousands of miles in a few days, and to descend as propagandists wherever the winds chonse to carry them, or for condensation to take place? In conclusion I beg to say that I would not attempt to repudiate the idea of predisposition altogether, but merely direct the attention of the public to facts probably equally important.

Whatever may be the origin of the fungus, says another writer, depend upon it, perseverance must be resorted to in order to get rid of it; if tubers are planted with a particle of it on them, and the season proves again congenial for its spread, it will again destroy the crop. As a proof of this I planted a few infected potatoes, without putting into practice the precaution $I$ have used with my other potatoes, and the consequence is that the obnoxious pest made its appearance in its usual blotchings, while a quantity of others, which I had stored in perfectly dry charred articles, are growing away healthily; a quantity with foliage and stalks above a foot in height, clear from spot or blemish, looks at present as well as could be wished. Depend upon it, the recommendation to shake lime about the tubers previous to planting, is most essential to prevent the further spread of the fungi, let the latter originate in whatever form they may, and should be immediately put into practice. Supposing every tuber intended for next season's production to be individually dredged with lime, an active boy would dredge a large quantity in a day; the expense would be trifling, either for material or 
labor; for lime can be easily procured in any quarter; for dredging, a box with holes is all that is required.

It appears to me, remarks another writer, that the disease primarily attacks the stem, and I think the view I take of the subject holds good in some cases, if not all. I maintain that it is a disease of the fluids; the descending sap becomes poisoned by the generation of unwholesome gasses in the stem; from the excessive moisture prevalent through this season, the proper exhalation of the plant has not been carried on; thus we find that the stem undergoes decomposition, instead of gradual decay, and this deteriorates the descending sap, which, passing to the root, poisons, as it were, the tubers. My own potatoes, which were planted on new ground, on a very steep slope, are not in the least affected. Where they were grown on higher ground, the tops died early, and the tubers are as healthy as possible. Before the last rain I dug about a rood - both from the lower and the higher ground, and all were equally sound. A few rows remained, which I was prevented by the rain from digging up; these $I$ have since gathered, and they have shown symptoms of disease; the tops were fine, but after the rain they were all matted together. During their growth $I$ never saw tops have a more luxuriant appearance, clear and fresh, with nothing like specks on the leaves or stems. Another thing which leads me to consider the sap as poisoned, is the great rapidity with which the tubers decay. They appear healthy to all outward appearance; still, in many cases, if they are kept several days before they are stored away, the specks are manifest ; first, of a dingy hue, then darker colored, and afterwards becoming soft and rotten. If this really is the case, I do not see of what use any of the methods as yet proposed can be. IIad the leaves or stems of my potatoes showed any signs of specks, I would have pulled the stems out of the ground, leaving the tubers a while before I dug them up; this would havo 
prevented any bad effect from a deteriorated sap. A proof might be obtained by comparing the analysis of an unsound potatoe with that of a sound one.

Mr. J. E. Teschemacher, who favors the theory of fungus, thus writes to the editor of the New England Farmer:

I hear, every day, of instances of parcels stored in cellars, apparently sound when put in, which are now totally worthless. Depend upon it, unless some remedy be found, it will hardly be worth while to plant potatoes another year.

In order that I may not be misunderstood, I will now succinctly state my opinions on this subject.

I think that salt, lime, and several compounds, will destroy the disease. I prefer salt, because, when mixed in the soil, it may get into the juices, and circulate through the whole plant. Lime, or lime water, would do the same to a certain extent, but it is far less soluble than salt.

The fungus $I$ have seen, vegetates upon and thickens the sides of the cells of which the potatoe is composed, which cells contain the grains of starch. The starch is not injured until the sides of the cells, rotted by the fungus, burst - the worms or maggots breed, and the whole finally becomes a mass of putridity, with an offensive, fungus-like smell.

I saw in your last week's paper, several cases of the disease occurring where sea-weed had been used, and also near the sea-shore. These cases would seem to militate against the idea of salt being a cure. But they are very far from convineing me, for the following reasons: The salt atmosphere near the sea, may not have contained one-tenth enough salt to destroy the rot, or the prevailing winds there may not have spread the spray in sufficient quantity. And with respect to sea-weed, in a late London journal, there are analyses of four different kinds of sea-weed, performed by burning the weed and analyzing the ashes. 
Ashes. Salt.

Laminaria saccharina gave to $100 \mathrm{lbs}$. about $10 \mathrm{lb}$. $3 \mathrm{lb}$. Fucus vesiculosus ". " 100 " " $20 \frac{1}{2}$ " $6 \frac{1}{2}$ "

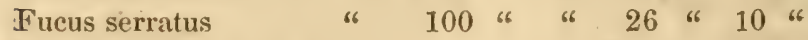
Fucus crispus, or

Chondria crispa " $\quad 100$ " " $25 \frac{1}{2}$ " $4 \frac{3}{4}$ "

They varied also considerably in the other ingredients. Now, when this great difference exists in the quantity of salt in different sea-weeds just taken from the sea, and when it is considered that the sea-weed is often made into a compost, turned over and exposed to all kinds of weather, by which salt may be washed out, it must be obvious that no true judgment can be formed of its effects on the potatoe disense, unless the kind of sea-weed, and all the attendant circumstances, be taken into account. The spores of the fungus, in the cases alluded to, might have been, and most probably were, so numerous, that the salt thus adventitiously obtained, was not sufficient to destroy them.

In a paper transmitted to the $N$. Y. State Agricultural Society, (alluded to in a former communication,) I recommended an analysis of sound potatoes, and a parallel one of those just contanrinated by the rot; and this to be done, not in the usual way, by reducing to ashes, but by expressing the juices and analyzing them. This would show whether there was any difference in the ingredients that might be considered as offering farorable circumstances for fungus regetation. The analysis by incineration should also be tried. For, if salt destroys the fungus, as my own eyes as well as those of others have seen, it is a fair presumption that if we can get a solution of salt into the juices of the plant, in any shape, that it will be unfarorable to the vegetation of the spores.

Until I see a number of experiments fairly tried with salt, lime, \&e., and they have failed, I shall not be persuaded that the riews I have taken of these as remedies for the potatoe 
evil, are erroneous, - and should they prove of no value, I am quite ready to give them up and try again.

A. B. Allen, Editor of the American Agriculturalist thus sums up, in a few words, the whole subject. The disease is probably a fungus. The best remedies are salt, lime and charcoal. We recommend procuring new seedlings, and be very careful not to let them get mixed with old ones. Plant next spring without other manures than plaster, salt, lime, charcoal or ashes. A good sod, with the addition of the other materials, will be sufficiently rich to raise a large crop; and, depend upon it, if the seed be of a good variety, and it escapes the rot, the erop will be sweet, mealy, and highly nutritious - the best for animals as well as for man.

As the disease is more generally attributed to the attacks of fungi than to any other cause, a few remarks on the cause of fungi, will not be inappropriate to this inquiry, and I give them place here. A writer in the Farmers' Cabinet says -

* Close observation will show, that all plants of the fungi tribe grow where there is a deficiency of alkalies. We never see mushrooms, toadstools, or any thing of the kind, grow on or near a heap of ashes or lime. But we almost invaribly see them growing on or near a pile of stalle dung, or any thing yielding a large proportion of carbonic acid. The cause of this is easily demonstrated by chemistry. A chemical analysis of plants of the fungi tribe, will show that they contain an extremely small proportion of alkali, far smaller than any other class of vegetables. The fact is of the highest importance to farmers; by its aid they can always tell when their soils need alkaline substances to make thern more productive, without going to the trouble and expense of a chemical analysis of the soil for that purpose. Upon whatever spot of ground the fungi make their appearance, there is a want of alkali, and no time should be lost in supplying it, if we would raise profitable crops; for such crops as wheat, 
corn, oats, hay, potatoes, \&c., will not grow well there, even if they are supplied with the very best stable manure. They need ashes, lime, dc., in such places, and they cannot do without them.

The fungi being composed principally of carbon, oxygen, and hydrogen, feed upon carbonic acid and water chiefly, and consequently if lime or potash be added to the soil where they grow, and the carbonic acid be thereby changed into a salt, the fungi have nothing to feed upon, and therefore die, for they cannot feed upon a salt.

When the potatoe crop has been furnished with sufficient alkali, particularly potash, and the carbonic acid in it in the form of a carbonate, the fungi have nothing to feed on, and do not attack the potatoe. On the other hand, when there is not sufficient alkali given to the potatoe crop to cause the carbonic acid to form a salt by union with such alkali, then the carbonic acid in the potatoc is in its own form of carbonic acid, and as such the sickly root offer's the proper food to the fungi, and it avails itself of it; unfortunately for doing so, it brings down upon itself the charge of being the cause of the potatoe discase.*

The same is the ease with other plants. If they lack alkali to form a salt in connection with the carbonic acid they receive, the superabundant carbonic acid will give nutrition to the seeds of fungi, and they will sprout and grow. We see this effect produced in wheat in the case of mildew, rust, or blight, and also smut in the same plant, the ergit in rye, the "devil's snuff-box" in corn, the mildew in oats, buckwheat

* Some of the practical chenists of this city, with their balances, tests, \&c., might do the agricultural community a great service in comection with this inatter, by analyzing sound potatoes, and giving their constituents; and then analyzing the rotten potatoes, and giving their constituents also. The public unight then compare them, and see what was wanted, and supply it. 
and the grasses, and the mossy growth on the bark of fruit and other trees. This is demonstrated by the fact, that if we apply strong alkalies in sufficient quantities to any of these plants, before they are attacked by the fungi, they will not be attacked; and if we supply them after they are attacked, they will soon be freed from them. It is to this purpose that our most suceessful farmers and fruit raisers apply salt and lime to protect wheat from rust, mildew or blight, and smut, and put ashes and lime upon corn to protect it from the "snuff-box," and sow ashes on potatoes to save them from the rot, and wash fruit trees with whale oil, soap or other alkaline substances, to restore them to health. These alkaline substances, too, by uniting with the carbonic acid, prerent the commencement of decay. This commencement in all carboniferous substances, is called, in chemistry, the saccharine fermentation, the product of which is a sweet substance, which gives food to flies, bugs, \&c., and which flies and bugs are also charged by other scientific gentlemen, with - being the cause of the potatoe rot, and other diseases of plants. The IIessian fly, in my opinion, finds nothing suited to its palate in a healthy stalk of wheat, or one that has enough alkali, and therefore does not attack it; but in a sickly plant, or one with a deficiency of alkali, she finds the sweet substance upon which she feeds, and there lays her eggs; which eggs, in the course of time, hatch and produce worms, and if the plant is in such a condition as to furnish food for these worms, they will still remain there; but a healthy plant will not furnish that food, - the same in regard to the wheat worm, muck worm, and all other worms that attack plants. I am led to this conclusion by numerous observations and some experiments. I have found that where there was a proper quantity of alkaline substances, plants were not injured by worms, bugs, or flies, in any other way than by being caten up by them. And, indeed, they are not so apt to bo 
eaten when they have a sufficiency of alkalies, for by their aid they form carbonate of lime, phosphate of lime, silicate of potash, \&c., and make their stalks and leaves so hard and strong as to be almost impenetrable to the attacks of many insects that infest them. And their juices are so insipid that they are not so well relished by such insects. 


\section{CHAPTER III。}

Causes of the Disease, and Remedies Stated.

I HAVE now given, as fully as my limits would permit, the most important particulars concerning the history, cultivation, and diseases of the potatoe. I have given the various theories that are entertained respecting the prevailing disease, and come now to state what I consider to be the causes of the malady that threatens a total destruction of the potatoe crop of the world, and the appropriate and simple remedies that will be found efficacious in staying its further progress in the crop of 1846 , and preventing it for future time.

The prevailing theories on the subject may be recapitulated as follows :-

1. Atmospheric influences.

2. Effects of manure.

3. Wet weather.

4. Dry weather.

5. Excessive heat and cold.

6. Deterioration of the plant.

7. Parasitical influences.

8. Attack of the mould.

9. Over cultivation.

10. Over ripening.

It must be evident even to the most superficial observer, that a cause must be found that is universal in its effects, because the disease has spread throughout the world, regardlesg 
of climate, soils or manures; warm or cold latitudes; in hot, dry, wet, and cold seasons; under every possible feature of cultivation, and in every condition of the crop, as managed by all sorts of farmers, throughout the whole of this country and all the countries of Europe. These facts remembered wo must diseard the idea that atmospheric influences would produce the disease; manures and soils could not produce it; excessive heat or cold could not affect the crop so universally. The disease has been steadily increasing for years in defiance of all the conditions that these various theories would establish as governing the nalady. They are partial in their operation, and must, therefore, be rejected as insufficient. The cause of rot, says an intelligent writer, cannot be in the soil, since we find healthy and diseased potatoes growing beside each other; that is to say, on soils of the same constitution we sometimes find the rot in alternate plants, or in whole rows. It cannot be attributed to the atmosphere, as all plants and roots are equally surrounded by it; nor can the cause be in the manure, as all the tubers receive the same kind, and nearly the same quantity. It must, therefore, be attributed to the potatoe itself.

We have, then, to consider the most popular theory, which ascribes the disease to the influence of the growth of fungi. This position is the one taken by the principal vegetable physiologists of Great Britain and this country, and most of the directions published in the agricultural papers are made with reference to this fact. That this is not the true cause of the disease, is, I think, made sufficiently clear by the concluding paragraphs of the last chapter. That evidenees of the appearance of fungi have been discovered, and are discoverable in all diseased potatoes, I do not deny, but I assert that they are a consequence of disease and not the cause. Liebig says in his Chemistry of Agriculture - "The microscopical examination of vegetable and animal matter, in the 
act of fermentation or putrefuction, has lately giren rise to the opinion that these actions themselves, and the changes suffered by the bodies stiljected to them, are produced in consequence of the developement of fungi, or of nicroscopical animals, the germs, or emgsi of which are supposed to be diffused every where, in a manner inaprreciable to our senses ; they are supposed to be developed when they meet with a medium fitted to give them nourishment.

"It is certain that sponges and fungi, growing in places from which light is excluded, follow laws of nutrition different from those governing green plants; and it cannot be doubted that their nourishment is derived from putrefying bodies, or from the products of their putrefaction, which pass directly into this kind of plants, and obtain an organized form by the vital powers residing within them. During their growth they constantly emit carbonic acid, increasing in weight at the same time, while all other plants, under similar cireumstances, would decrease in weighlt. IIence it is possible, and indeed probable, that fungi may lave the power of growing in fermenting and putrefying substances, in as far as the products arising from the putrefaction are adapted for their nourishment."

The truth with regard to the appearance of fungi in potatoes is, then, simply this:- The disense exists in the potatoc; putrefaction talies place, and these germs or eggs which Liebig supposes to be every where, find in the diseased potatoe their proper nourishment, and hence they begin to grow. If, as is asserted, the germs of fungus are diffused every where, why do they not affect all other crops, in a similar manner? Simply becanse other crops are not diseased. But over-ripe vegetables, fruit, and decaying or putrefying regetable substances are affected in a similar degree, because they are putrefying: they are not putrefying because of the fungus.

But, admitting for a moment that the presence of fungi is 
the cause of rot, a certain and immediate remedy is at hand; for, "when the potatoe crop has been furnished with sufficient alkali, the fungi have nothing to feed on, and do not attack the potatoe;" and further, "if we apply strong alkalies in sufficient quantities to any plants liable to altack from mildew, rust, blight, \&c., (which are rarious developements of fungi,) before they are attacked, they will not be attaclicd, and if we supply them after they are attacked, they will soon be freed from them." Now alkalies have been applied in considerable quantities to potatoes, and while growing they have not been attacked by the rot, bit after gathering and harvesting disease has appeared and destroyed them, showing conclusively that fungi is not the eause, but that a deeper one must be sought and a more radical remedy applied.

What, then, are the causes of this extensive evil? I state them thus:-

\section{Over Ripening, \\ Over Cultivation, \\ Deterioration of Seed.}

'To which might be added,

\section{Carelessness in Selecting Seed.}

In this last particular great losses have been sustained by farmers, not only in the potatoe crop, but in every crop that is cultivaterl. $\Lambda$ nd this disaster to potatoes may, as its cause is discovered, eventually prove a blessing, by showing the prime importance of selecting good seed. It is surprising that farmers will obey almost every law that must be observed in good cultivation, and yet neglect to supply themselves with seed, properly saved and cured. It admits of demonstration that much of the losses arising yearly in the various crops of our agriculture, are traceable directly to the want of good and pure seed. Of what use, I would ask, is thorough cultivation, plowing, hoeing, pulverizing and manuring, if the grand object for which all this labor is expended 
is not promoted? and how can it be accomplished without good seed? Cultivators have practised as though that was a matter of no importance, and yet, it would seem, every year's experience would teach them better; for, do they not sec, every season, how much quicker sales and better prices farmers receive for good products than for those which are inferior? and yet they say, it is their neighbors' luck, when it is clearly the result of judicions foresight.

$\Lambda$ false economy prevails on this subject. Many farmers look for seeds of the lowest price. This is wrong. The best and purest seeds are always the cheapest, and in excreising a proper economy, they ought to select seeds that are known to be pure, healthy and strong, without regard to the price, provided it is within reasonable limits.

There is a great atvantage in pursuing the right course in regard to this matter. An increased product of one half bushel on an acre in the average yield of corn, wheat, rye, oats, barley, \&.e, will make in the aggregate a rast amount; and yet by using seecls that are carefilly sclecterl for their purity, healthiness and strength, how much more than an average increase of one half bushel per acre can be realized? In some cases from one to ten bushels, and even a greater increase can be oltained by attending to the selection of seeds.

It will be found on inquiry that those farmers who are the most successful in producing large crops, spare neither time, labor nor expense, in selecting their seed. Differener of soil, situation, manures, and previons condition of the land, are to be considered; but it will appear that the quality of secd sown has influencerl the (quantity of the cron as much, if not more, than any other circumstance.

But it is not the increalied quantity of a crop that is the only advantage gained in using selected seed. Another advantage is, the superior quality of the crop, and this alone, allowing that the average yicld was the same in using good 
and bad seed, is a sufficient inducement to be very particular in the selection. It has not escaped the observation of the most careless purchaser of agricultural produce, or the experience of producers, that there is a vast difference in the market value of crops of the same variety. Whence does this difference arise? One crop is raised on a congenial soil, with congenial food, and with better cultivation thun another had, but after all, it will be found that the quality of seed used, influeneed the value of the crop as much as any other consideration. Take the article of potatoes. Some varieties sell, in ordinary seasons, at retail, in Boston Market, for one dollar per bushel, while the main stock is offered at thirty to forty cents per bushel. The first are mealy, almost every potatoe good, and nearly equal to wheat bread, while the others are close, sogrgy, clogry, half-decayed things.

"Potatoes, which not fit to dig, Would turn the stomach of a pig."

Which are most profitable for farmers and consumers? What is observed of potatoes is equally true of every other kind of marketable produce.

Perhaps in no part of the duties of the farmer has there been so much neglect as in selecting and saving potatoes for seed. Any potatoes have been considered good enough for that purpose, and any mole of preserving or keeping them las been adopted. Now, to this one fact, we trace a portion of the evil that has risited us in the potatoe crop. $\Lambda$ greater mistake never was committed. To build a house with unburnt bricks were wisdom compared with it.

By improper management in taking up the potatoe, tubers of the finest quality are easily spoiled; and, on the contrary, by judicious treatment, even such as are watery may be considerably improved. It is of the highest consequence that light as well as frost should be guarted against; for light renders the 
tubers unwholesome, and that, in proportion to its intensity and the length of time the tubers are exposed to its influrnec.

The stems, and in fact all parts of the potatoe plant above ground, are more or less poisonous. Tubers are occasionally formed along the stem, hut they are, as we all know. green and barl. This is entirely owing to their exposure to light; for had the stems been laid in the earth, so as to have corered such stem-tubers from the commencement of their growth, they would have been just as good as tubers of the underground formation. Potatoes, even in their dirty state, as taken up, will be considemahly altered in color, both externally and internally, and proportionably impaired in quality, by a few days' exposure to light, in clear weather, although they may not he exposed to the sun's direct rays; but the effect must be greater when the surface is washed and deprived of the partial shade afforded hy the particles of soil.

The time was when potatoes were in many instances spread ont in the sun, in order to dry them before storing in the eartl. No practice conli be worse, for the reasons ahore stated; and, moreover, the olject in view, that of rendering them ultimately drier and better in quality, was not attained. On the contrary, although depriverl of a portion of their moisture in the first instance, yet this only left room for the absorption of moisture contaminated with gasses, generated in the place where they were stored.

From this I would have it inferred that potatoes shou?d never be cleansed or washed before they are stored; they should be dried with the dirt remaining upon them, as they were taken from the gromul, but with the least possible $\mathrm{x}-$ posure to light. Potatoes for seed may remain so until it is time to plant them; those intenderl for cooking may be taken out and dried several days before they are wanted for use. A writer in the Recue Forticole, a French agricultural publication, is aware of this fact. IIe says: "In unfurorable 
seasons potatoes are always found to be watery and without flavor, although cooked with the greatest care. In this case the mode of effecting an amelioration is easy; it consists in placing them near a stove or oren, for about a week previonsly to their being userl; at the end of that time they will be found mealy and of good flavor." Objects of vast importance are sometimes attained by very simple means; and that to which the foregoing remarks apply, is by no means underserving consideration. At a meeting of farmers in Scotland, they gave clearly the results of their varied experience, and one firet all the speakers seemed to agree in, which was, that potatoe.s left in the gromm, where they grew, always produced a healthy crop. Many farmers confirm this. One farmer says he has followed this same plan forty years with uniform suefess; the potatoes were always fresh and well tasted, and as seed, they never failed. Ilere is the simplest of all plans for saring seerl, for a little extra earth will secure them from frost. It is stated by some that extra earth in saving potatoes is unnecessary. If they are in a dry soil, and completely covered by it, they will not be injured by the most severe frost - that is, supposing they are to remain in the soil until they are completely thawed again. IIundreds of potatoes are left in the ground all the winter, many of them not more than an inch deep, and yet when they are turned up in the spring, they are as sound as if they had been kept in a cellar.

It has been thought that the sprouting of potatoes in celliurs must have some effect on the liealthy developement of the future plant, and it would seem that there is some reason for this idea, "as in the town of Ballina (Ireland) where the rot lies never appeared, I have been toll that all farmers, from the richest to the poorest, take especial care to select those potatoes which have never sprouted in cellars, and to plant them as quick as possible. It is said, however, that 
the crops there are begiming to fail, owing to the practice of planting year after year on the same soil. They do not rot but get smaller in size. An allkali of a very defeterious nature (Solenin) is found in the spronts of potator's which shoot in cellitre, while not a trace of it is found in sprouts grown in soil. IIow far this temls to injure the tuber is not ascertained, but it is highly probable that such a tendeney is inducerl. It is not proballe that the degeneration of the tuler in one year immediately induced rot, - by nerglect, transformations have been going on for years, which have ultimately led to it. Experiments might easily be instituted to show how far shonts produced in cellars affect the crop, and it is certainly worth ascertaining.

Ovir-Crutratron. What las been said on this subject in the foregoing pages should be re-perused with care and especial attention, as this is one of the main causes that has produced the grent evil. It may be asked, indeed it will be asked, "If rot arises from this, and the other causes you have named, why lias not the evil appeared before, and why is it so universal now?" I answer, that while the crop was produced by manures that are not highly stimulating, on land that did not contain a superabundance of nutritive matter, and while the quantity produced per acre was moderate, the disease was not developed; that in the interior, away from cities and large towns, there was no trouble with the crop for a great number of years; that in the immediate vicinity of cities where manure is abundint, and the land highly fed, the disease made its appearance in a very carly stage of the cultiration of the crop, and its progress was only stayed by yearly importations of seed from back countries; that the disease has been steadily increasing for years, and it is not a new disease, but has progressively increased wherever the crop is cultivated; that the manner of saring and preparing seed, growing crops, manuring and cultivation is, and has 
been, very nearly the same, in all the countries where the potatoe is grown, and, consequently, all the causes which produce the disease, have been simultaneously in operation, everywhere. 'That the disease is not an epidemic, we know, because somit and unsound potatoes are grown upon the same field. I say that the causes of the disease lie where I have placed them, because in almost erery instance where the treatment of the crop has been based upon this theory, there has heen no rot. There are, of course, exceptions to all general rules, and exeeptions may be named to this, but the great fact remains ture, and it will be a demonstrated truth next year, hy all who are careful in selecting land and preparing their seed potatoes.

Now I lay it lown as an incontrovertible fact that potatoe sets from a higlily cultivated field, and from a large cropl, are not proper for sechl, and that sets from such a crop will inevitably give a diseased proluct; it may not he visible the first year, or the second; but the tuber is diseased, and the diseace will ont. I do not say that farmers should not strive for large crops, lut merely that sets should not he taken from them. I cannot precisely state the law goreming this fict, lut it has been remarked by Professor Morren that the potatoe is not a root - only a branch; and if the Professor is correct, then an easy solution for it is at hand. The plant, by over-production, has exhausted its vital energies. And this would seem to be the true reason why sets from such a crop are not proper for seed.

Over-Ripening. Another cause to which I ascribe the rot, is the planting of over-ripened sets. I believe it will not be entended for a moment that orer-ripened sets have not generally been planted, neither will it be asserted that the produce from sets not over-ripened have been, to any general extent, affected by the disease. In some cases they have; but, then, it will be traceable to pre-existing disease, arising 
from the same causes in previons years. There is no question that the vital energies of a pl:ant, if excited bryoul at given point, are injured in their organization, and renleres unft for the purpores of reproluction. I spenk now of those plants which-are rejroluced by cuttings, layers, and tulerous appendages growing from them. Florists who, lyy the nature of their lusiness, are obliged to watch the nature of all plants propagated by these means, mulerstand the opreration of this principle, and the individuals they proplagate from are generally selected with greatest eare. The rules which apply to other root cropse, will not and camnot apply to potatoes, because other root crop's are repuroduced by seed, and cannot be produced by euttings, sets, or tubers. The potatoe set is part of the plant; it is forreel from its parenit stem to perform the unmatural office of perpetuating its kind. Now, this fact borne in mind, it will he seen that the causes which I have named as producing disease, are the most obvions, as well as the most natural ones, and it is the simplicity of the thing alone which has prevented the deeply learned and scientific from making the discovery before. They late undoubterlly made observations on these canses and understand fully the operation of them, but as they were simple and evident, have passed them by as of no immediate consergnence.

The same thing may be remailied with regard to progress in morals. religion, and any of the sciences. Professars in these hranches of linowledger, have rot distingui-hed themselves, by any wonderful additions to their subject; they only arlopt, apply, and illustrate linomen truths. New discoveries they make not; they are things unknown; they search for them, incleed, but look for profound and mysterious laws, forgetting that all the truths in the areana of nature, are so simple that a child can umlerstand them. This rule of thought and action has prevented progress from the earliest ages to the present time, and a modern professor will be as 
likely to sneer at my simple theory and remedies as was Naaman, the Syrian, when told by the prophet to wash seven times in Jordan, and he should be healed. The prourl official turned away in anger and scorn, but a serving girl followed after him, and asked, in the language of simple common sense, and accoriling to the strict rules of analogy: "My lorl! if the prophet had bid thee do some great thing, wouldst thou not have done it?" The multitude misconreive the operations of nature: they are continually looking for great things, and let opportunities slip that would induct them into a more intimate knowledge of the ways of Providence. Putting water upon fire is a simple remedy, but it is efficacions. "Cease to do evil; learn to do well," is a simple remedy to amend a barl life and barl habits, but it is alundantly able to transform a spirit of darkness to assimilation with the purity of angels. It is by looking for simple causes that the greatest results are obtained.

Deterionation of Seed. All the causes we have named would maturally tend to the deterioration of potatoe sets, and it is not at all surprising that most of the seeds of varieties now in use, have become so weak and disorgnnized as to prodnce discasol tuliers, and so furnish food for fungi, and an excuse for ascribing the general decay to all the other canses that hase heen assigned. Mr. Kinght, the first

- President of the Londen Morticultural Society, and one of the greatest men of his time, limited the duration of varieties in a state of perfection to from fourteen to twenty Jears, and remarked that the experienee of most farmers would witness for him that no variety, then in cultivation, and esteemerl a good sort, could be traced back more than twelve years. On the other hand, it has been stated, aud individual experience

- has proved, that with eare, varietice have preserved their original vigor for nearly half a century. This last is no doulut the truth with rezard to varieties, if proper care has been 
observed in managing the seed or tubers from them; but the remark of Mr. Finight will hold generally correct in view of the very extensive and deplorable mismanagement that has prevailed in saring sets for replanting.

Now, having staterl the eanses of the potatoe plague, rot, or taint, the remedies to be applied are easily understood and within the reach of all. Sets from this year's crop, that have escaped change, may be carefully selected, and though they may be affeeted by previous mismanagement, the disease will not prevail so extensively in the new crop as it did last year; hy cultivating expressly for seed, storing and saving them, as recommended in this book, another year will witness a great fatling of 'in the disease, and, erentually it will disappear, as none but healthy sprouts being planted, disease cannot be propagated.

On the subject of planting potatoes, the following remarks by Mr. T. Smith may be appropriately inserted in this place. "From the experience I have had in the cultivation of the potatoe, I have come to the conclusion that the taint, or dry rot, owes its origin entirely to an injudicious method of planting the seed; * and after mature consideration, I have adopted a system of planting, which I have practised for twenty years, with such success as never once to have had an instance of dry rot among my potatoe crops during that time, although they were sometimes growing in direct contiguity to other potatoes, which, from being planted in a different manner, were laboring under the effects of disease. It shall now be my endeavor, in as simple and as concise a manner as possible, to lay this system before my readers, conrinced that

* Much difficulty has doubtless arisen from this source, but it is vain to ascribe the rut entirely to it. The suggestion is, however. worth attending to, as improvements in planting, as well as in selecting seeds, must be advantageous. 
they will find it in practice a most effectual remerly for the disease in question. The chief cause of this disease I conceive to be the prevalent error in planting the potatoe, of placing the seed in a quantity of dung laid in the middle of the drill. Any one who knows any thing of the qualities of dung, knows that it is of itself incarpable of promoting vegetation, or sustaining regetahle life, until decomposed, and incorporated with a portion of earthy soil, and it is not therefore to be wondered at that disease and failures in the potatoe crop are so prevalent. The wonder is, that while such a system of planting is persevered in, any of these crops should succoed at all under such treatment; and, indecd, this is only to be accounted for by the small quantity and inferior quality of the dung applied, which is generally found mixed with great quantities of half-rotten straw and other extraneous substances, and were it not that the fresh earth is laid immediately on the top of the dung after the seed is planted, the failure of crops would be to a much greater extent; of this I have no doubt. The ground too, if in a very imporerished state, may, by speedily digesting and drying up the dung, prevent, to a great extent, a total falure of the crop, although the seed were planted thus injudiciously in the midst of the dung ; for it will be observed that in such ground the rot is not so destructive as in rich deep soils. The first and great point, therefore, in setting the potatoe, is to have the manure properly commingled with the soil before introducing the seed, the plan I arlopt in planting, briefly as follows: In preparing a parcel of ground for the reception of the potatoe seed, I proceed to have the manure spread regularly over the surface, and evenly dug in. I then cither drill the ground, after the manner of gardeners in sowing peas, and plant the potatoes in the drill, or plant them with a dibble, without drilling, about two or three inches below the surface, the dibble being formed with a broad point, so as to insure the 
potatoe having no open space left beneath it, when dropped into the hole. For large fields which eamnot well be dug or planted in this manner I would recommend that the ground be prepared and the dung spread exactly as for oats or barley. Then have the ground drilled, and in planting place the seed potatoe in the clear soil, on the back of the half drill, formed by the return of the plough, which half drill should be made larger than ordinary, to bring the seed as near to the centre of the drill as possible, so as to afford it every advantage of the fresh soil to regetate in. In this way, the fructifying earth, in which the seed is embedded, will secure its healthful vegetation, and as it progresses in its growth, and so soon as it throws out roots, it will reap the full benefit of the manure contained in the surrounding soil. It is of the utmost importance to have the seed planted, so as it may have the earth both below and above it when put in ; for in keeping the seed free from the dung, I apprehend, lies the whole secret, which should be particularly attended to." 


\section{A P P E N D IX.}

\section{T A B L E}

Of the number of sets of potatoes, and total weight of the same, required for planting an acre at the following distances; each set containing a single eye and weighing half an ounce; the distance between the sets in the rows being nine inches.

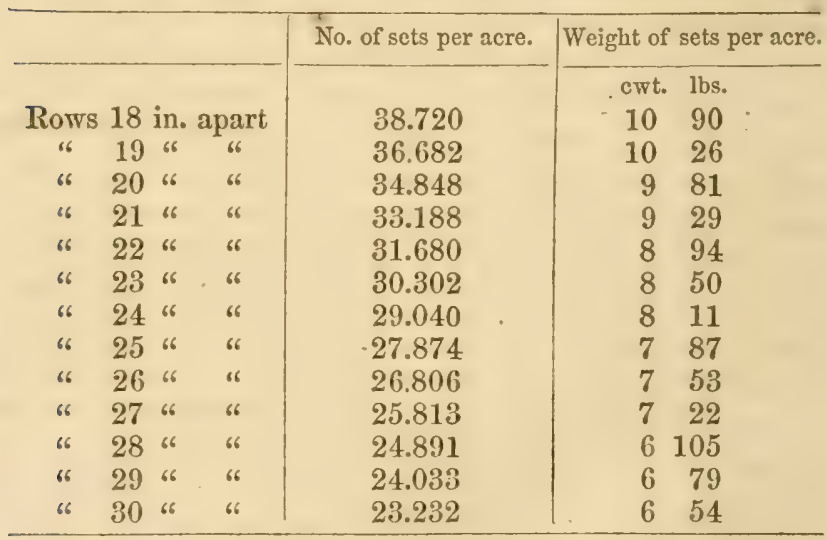

On poor soil, eighteen inches between the rows may be considered a proper distance, as may likewise be the case 
with early weak-stemmed varieties on any soil. And according to the vigor of the stems, richness and depth of soil, the distance may be increased to thirty inches, which is wide enough for the strongest growers, eren on rich soil.

It is to be remarked that in some varieties the eyes are not abundant. With regard to such the above number of sets will not be olstained from the corresponding weights; but in general it will be practicable, provided sound eyed tubers can be employed.-Robert Thompson. 


\section{ON PLANTING CUT AND UNCUT POTATOES FOR SEED.}

AN important point which potatoe growers have taken for experiment is the difference in produce where whole tubers and cut sets are employed. There is a great difference of opinion on this subject.

A good many farmers are in favor of using whole tubers. One cultivator says: "I always use whole potatoes, which insures a tolerable crop in all seasons, preventing $d r y$ rot in hot weather, and rottenness in wet weather, which cut potatoes are so liable to." A Leicestershire farmer says, that after many years experience he has discontinued planting cut sets, and substitutes whole tubers, selecting small ones, but not the smallest; he adds, that adopting this rule, he has had an excellent crop this year, and the tubers are extraordinarily. large. A furmer near Birmingham finds his cut sets a total failure, and another gives a decided preference for whole potatoes, the poor people haring lost almost all their cut sets, while their whole potatoes stood the long drought.

\section{[From the Genessee Farmer.]}

Mr. Tucrer, - I planted last spring, three acres of potatoes. One half of the ground was ploughed in the fall of 
1837, and the other in the spring of 1838 - the whole a clover pasture in 1837. The part ploughed in the spring had sixty large wagon loads of straw from the barn yard put on and turned well under the sod - that part ploughed in the fall was well harrowed and cultivated and then furrowed shallow, and the seed dropped in drills, and fifteen loads of straw and sheep manure, taken from the sheep sheds, put in the hills over the potatoes. This piece was decidedly better than the first mentioned. The ground was naturally moist, and the excessive rains of the springs washed and drowned the seed very bad, so as to destroy more than a half acre, on part of which I planted on the 4th of July early white beans, from which I harvested three bushels of sound beans. Yet notwithstanding the bad season and rains, I harvested seven hundred and fifty-five bushels of potatoes, mostly pink eyes, the remainder a flesh colored (not the Sardinia,) which I call long keepers, from their being a better potatoe for summer's use than the pink eye. But the object of this communication is to give you the result of my experiment in 1838, on the quantity of seed required.

$\begin{array}{cllr}\text { Row. } & \text { In each hin. } & \text { Yield. } & \text { Qual. } \\ 1 \text { planted } & 1 \text { whole large pink eye } & 41 \frac{3}{4} \text { lbs. } & 8 \\ 2 & 2 \text { middle size } & 42 & 10 \\ 3 & 1 \text { do. } & 41 \frac{1}{4} & 5 \\ 4 & 2 \text { halves } & 32 \frac{1}{4} & 9 \\ 5 & 1 \text { do. } & 39 \frac{1}{2} & 3 \\ 6 & 2 \text { quarters } & 25 \frac{1}{2} & 4 \\ 7 & 1 \text { do. } & 37 \frac{3}{4} & 1 \\ 8 & 1 \text { very small } & 40 \frac{1}{2} & 2 \\ 9 & 2 \text { do. } & 41 & 6 \\ 10 \text { large potatoes cut in } \frac{3}{8} \text { and drilled } & 39 & 7\end{array}$


The above yield was obtained from rows $1 \frac{1}{2}$ rods long and 3 feet between the hills each way (measured, not guessed at.) The quality numbered according to size, No. 7, decidedly the best, and No. 2 had but few large enough to cook.

I have for seven years assorted my potatoes at the time of digging, and fed the small ones to my hogs, and then in the spring I again select a few bushels of the largest, and best-shaped ones, and plant by themselves and save my seed for the next year from the product of those selected, and in no event planting a potatoe that the women had Ieft as too small to cook. The above, I think, will sufficiently account for the good yield and quality of No. 8. I do not believe, with Solon Robinson, that whole potatoes are better than cut ones. If any person would give me the seed if I would plant whole pink eye potatoes, I would not take it, preferring to use a half one of my own raising. I- have just received an order for 40 bushels of pink eye potatoes for seed, from a gentleman in this county, to whom I solk the same quantity last spring, in which he says, "the potatoes I had of you last spring, were planted according to your direction on four acres of ground, and I have harrested over 1200 bushels the finest I ever saw, and I prefer purchasing seed of you to planting those raised on my own ground." By persevering in the above practice of saving seed we have increased the size of our pink eye potatoes one third, and the yield has nearly doubled.

I remain, yours, \&c.,

S. Porter Rhodes.

Skaneateles, Feb. 18, 1839.

[From the Maine Farmer.]

Mr. Holmes, - Sir, I propose giving the result of experiments which $I$ made the past season on seeding the potatoes. 
Perhaps your readers remember I last spring promised to make such experiments and communicate the results to the Farmer.

I carefully selected a piece of ground of eren soil, consisting of 16 rows of 20 linlls each. I manured it in the hill as erenly as possible. I then weighed the seed and planted eight rows, commencing on one side, each row with different seed, in the order observed in the tables below. I then planted the eight remaining rows, commencing on the other side in the same order, so that if my experiment ground were better on one side than it were on the other I should be likely, from a combined experiment, to obtain a fair result.

I shall give the results of the experiments separately, that your readers may see there exists a similarity in them.

I dug, counted, and weighed separately, the product of each row, and after deducting the weight of the secd, as was very important in order to arrive at a correct conclusion, as the weight of the seed varied from $7 \frac{1}{2}$ to $19 \frac{1}{2} \mathrm{lbs}$. I found the result exactly as follows.

\section{First Experinent.}

Seed ends,

Middles,

Buts,

Large whole,

Small whole,

Cut longintudinally

Double seed,

Drills,
Weight.

54

$49 \frac{3}{4}$

58

$67 \frac{1}{4}$

$62 \frac{1}{3}$

57

56

$61 \frac{1}{2}$
No. per $60 \mathrm{lbs}$.

274

316

317

286

241

234

329

310 


\section{Second Experment.}

$\begin{array}{lcc} & \text { Weight. } & \text { No. per } 60 \mathrm{lbs} \\ \text { Seed ends, } & 55 & 282 \\ \text { Middles, } & 51 \frac{3}{4} & 318 \\ \text { Buts, } & 55 & 339 \\ \text { Large whole, } & 55 \frac{1}{4} & 275 \\ \text { Small whole, } & 49 \frac{1}{2} & 287 \\ \text { Cut longitudinally, } & 61 & 274 \\ \text { Double seed, } & 51 & 340 \\ \text { Drills, } & 91 \frac{1}{2} & 324\end{array}$

Combined Results.

Seed ends,

Mriddles,

Buts,

Large whole,

Small whole,

Cut longitudinally,

Double seed,

Drills,
109

$101 \frac{1}{2}$

113

$122 \frac{1}{2}$

112

118

107

124
278

317

328

280

264

254

334

317

If your readers feel the interest in following out these experiments and reducing them to practice which $\mathrm{I}$ felt in making them they will do it.

[From the Albany Cultivator.]

There is hardly any crop about the management of which a greater diversity of opinions exisis than this - whether we regard soil, seed, or mode of planting and culture. The British Board of Agriculture, with a view to ascertain the best mode of managing the potatoe crop, aldressed a number of 
queries to the principal farmers in the kingdom, calculated to elicit the fitets necessiry to determine this point. The circular and the answers were published in a large quarto volume, together with the report of the committee charged with the arrangement and publication of the facts. The statements are so variant, that the committee were unable to recommend any particular practice, as that which was most successful in one case, proved defective in other cases. The only important fact settled by the inquiry was, that potatoes differ very materially, in some cases fifty per cent., in their nutritive properties, a consideration as material for the stall as for the table. Since the date of that publication, however, very nice experiments have been made in Great Britain, particularly in Scotland, and by Mr. Knight, and also in the United States. From these we draw the following conclusions:

1. That in this latitude the potatoe is better, both as to produce and flavor, when grown on a moist and cool, than when grown on a warm and dry soil - better on a moderately loose and friable, than on a hard and compact soil.

2. That they do better on a grass lay than on stubble and better with a long or unfermented manure, than with short muck.

3. That medium sized whole tubers give a better crop than sets of very large tubers.

4. That drills or rows should be adapted to the growth of the tops, and the condition of the soil - the small growing tops nearer, and those having larger tops farther apart - so that the sun may not be excluded from the intervals; and where the soil is stiff, or the sorl tough, hills are considered preferable to drills.

5. That if the ground be well prepared, and the seed well covered, they are not bencfited by heavy earthing; and that plowing among them, or earthing them, after they come in bloom, is prejudicial. 
6. That the kinds best for the table, are also best for farm stock, containing a larger portion of nutriment than inferior kinds.

While upon this subject, we will mention that our friend, Capt. Joab Centre, who some tome ago left plowing of the deep for plowing of the glebe, has invented a potatoe plow, which is said greatly to facilitate the gathering of the crop. As soon as we become satisfied of its utility from our personal knowledge, we intend to give a cut and description of it. 







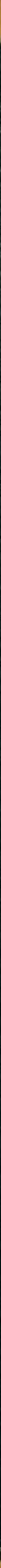

